\title{
Molecular specification of germ layers in vertebrate embryos
}

\author{
Clemens Kiecker $^{1} \cdot$ Thomas Bates $^{1,2} \cdot$ Esther Bell $^{1}$
}

Received: 8 June 2015/Revised: 11 October 2015/Accepted: 9 November 2015/Published online: 14 December 2015

(C) The Author(s) 2015. This article is published with open access at Springerlink.com

\begin{abstract}
In order to generate the tissues and organs of a multicellular organism, different cell types have to be generated during embryonic development. The first step in this process of cellular diversification is the formation of the three germ layers: ectoderm, endoderm and mesoderm. The ectoderm gives rise to the nervous system, epidermis and various neural crest-derived tissues, the endoderm goes on to form the gastrointestinal, respiratory and urinary systems as well as many endocrine glands, and the mesoderm will form the notochord, axial skeleton, cartilage, connective tissue, trunk muscles, kidneys and blood. Classic experiments in amphibian embryos revealed the tissue interactions involved in germ layer formation and provided the groundwork for the identification of secreted and intracellular factors involved in this process. We will begin this review by summarising the key findings of those studies. We will then evaluate them in the light of more recent genetic studies that helped clarify which of the previously identified factors are required for germ layer formation in vivo, and to what extent the mechanisms identified in amphibians are conserved across other vertebrate species. Collectively, these studies have started to reveal the gene regulatory network (GRN) underlying vertebrate germ layer specification and we will conclude our review by providing examples how our understanding
\end{abstract}

C. Kiecker and T. Bates contributed equally.

Esther Bell

esther.bell@kcl.ac.uk

1 MRC Centre for Developmental Neurobiology, King's College London, Guy's Campus, London, UK

2 Present Address: Leibniz Institute on Aging, Fritz Lipmann Institute, Jena, Germany of this GRN can be employed to differentiate stem cells in a targeted fashion for therapeutic purposes.

Keywords Mesendoderm · Nieuwkoop Centre · Spemann organiser - Induction · Nodal $\cdot \mathrm{Vg} 1 \cdot$ Activin . Wnt $\cdot$ FGF $\cdot$ TGF $\beta$

\section{A history of germ layers leading up to the three- signal model for mesoderm formation}

In the second half of the eighteenth century Caspar Friedrich Wolff noted that the cells of an embryo are organised in layers, and this observation formed the foundation of the concept that embryos consist of germ layers, developed in the nineteenth century by Heinz Christian Pander. The end of the nineteenth century was marked by the advent of experimental embryology and, based on their famous grafting experiments in amphibians, Hans Spemann and others established the concepts of embryonic induction and competence. Somewhat surprisingly, germ layer formation attracted relatively little interest at that time and the work of the embryologists focused on the formation of more definitive tissues such as the brain, limbs and eyes. However, in his classical fate mapping studies Vogt already mapped the origin of the mesoderm to the involuting marginal zone ("Randzone") of the gastrula of different amphibian species (Fig. 1a) [1]. This led researchers to realise that the germ layers become established during the process of gastrulation.

In the first half of the twentieth century, the search for embryonic inducers led to occasional cases of mesoderm induction [2]. The inducers in these studies were typically heterologous (extracted from adult tissues, often of other species) and thus their biological relevance remained 

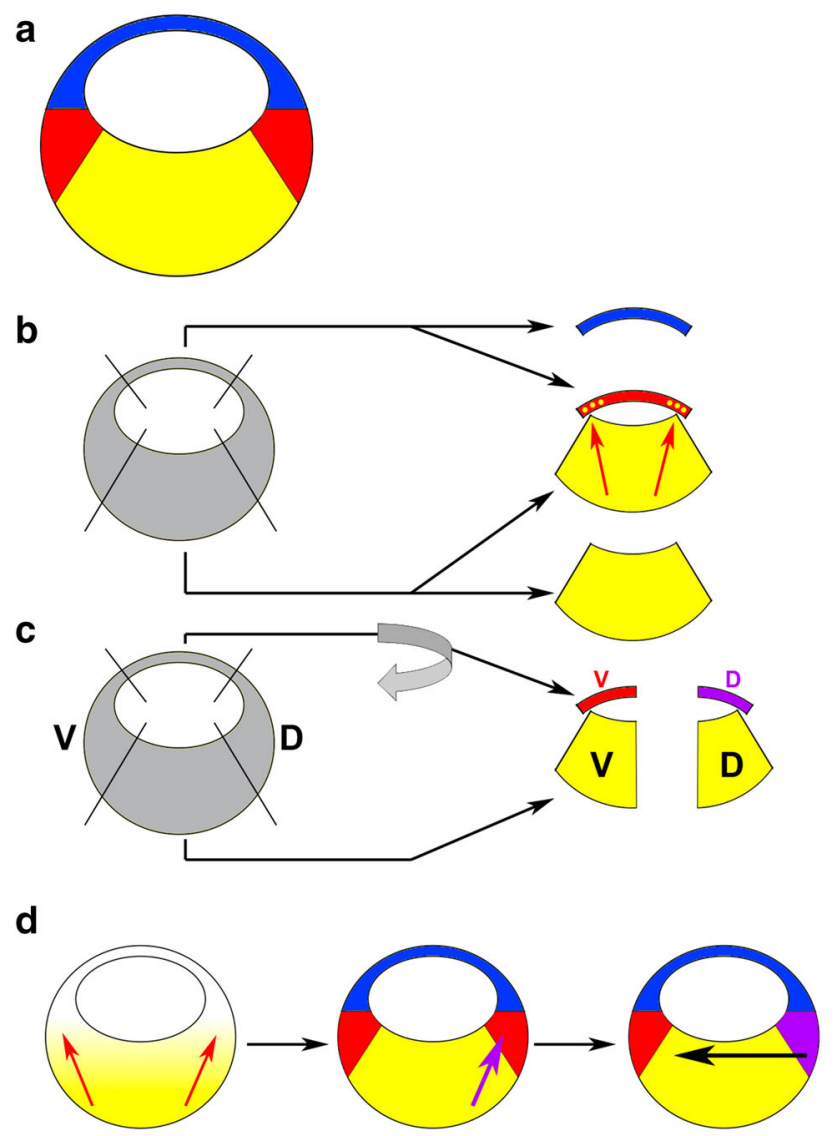

Fig. 1 Experiments leading up to the three-signal model (3SM). a Schematic of an amphibian late blastula stage embryo after germ layer induction; animal points up, vegetal points down, ectoderm is shown in blue, mesoderm in red, endoderm in yellow. b When cultured in isolation, animal and vegetal explants differentiate into ectoderm and endoderm, respectively; in animal-vegetal co-cultures, mesoderm (and some endoderm) is induced in the animally derived tissue suggesting an inducing signal emanating from the vegetal tissue (red arrows). c Dorsovegetal cells induce dorsal mesoderm (purple) whereas ventrovegetal cells induce ventral mesoderm, even if the animal tissue is rotated by $180^{\circ}$. d The 3SM for germ layer formation: (1) a signal emanating from vegetal cells of the embryo induces the mesoderm in an equatorial ring (red arrows), (2) a signal from dorsovegetal cells dorsalises the mesoderm on the dorsal side (purple arrow) and (3) signals from the dorsal mesoderm (Spemann's organiser) pattern the embryo along its DV axis (black arrow). $D$, dorsal; $V$, ventral

questionable. It was only in the 1960s and 1970s that Pieter Nieuwkoop and his colleagues published a series of seminal studies that identified mesoderm specification as an inductive process between the vegetal cell mass (endoderm) and the animal cap (ectoderm) of a blastula stage salamander embryo. Specifically, Nieuwkoop found that vegetal cells form endoderm and animal cap explants form ectoderm when they were cultured in isolation, but that mesoderm was induced when both types of tissues were cocultured as aggregates [3]. Nieuwkoop could also show that not only mesoderm, but also pharyngeal endoderm were induced in the co-cultures, and that the induced mesendoderm (cells that can differentiate into both endoderm and mesoderm) was entirely derived from the animal cap component of the aggregates, suggesting that an inducing signal emanates from vegetal cells (Fig. 1b) [3]. Therefore, it was clear that mesoderm and endoderm formation require inductive signals.

In these experiments, Nieuwkoop also showed that there is a dorsoventral (DV) bias within the vegetal cell mass such that dorsovegetal blastomeres induce dorsal mesoderm whereas ventrovegetal blastomeres induce ventral mesoderm (Fig. 1c) [4]. The dorsal marginal zone (DMZ) is where the involution movements of gastrulation begin, and Spemann and his colleagues had demonstrated previously that the transplantation of tissue from this region at the onset of gastrulation to the ventral side of a host embryo resulted in the formation of a second body axis. The ectopically induced twins contained only few cells that came from the grafted DMZs and most of their tissue was derived from the host embryos, indicating that the early gastrula DMZ can organise the formation of a fully patterned embryo in surrounding tissue [5]. These experiments coined the term 'Spemann organiser' for the early gastrula DMZ and won Spemann the Nobel Prize in Medicine in 1935. Nieuwkoop's studies suggested that the dorsal mesoderm including Spemann's organiser is induced by dorsovegetal endodermal cells, and this "organiser of the organiser" is often referred to as the 'Nieuwkoop Centre'.

These and other experiments led to the 'three-signal model' (3SM) for mesoderm formation (Fig. 1d): (1) vegetal cells secrete a mesendoderm-inducing factor that converts the marginal zone into a ring of mesoderm, (2) the vegetal cell mass is subdivided into dorsal and ventral parts that induce dorsal and ventral mesoderm, respectively, and (3) the most dorsal mesoderm (Spemann's organiser) secretes signals that establish DV polarity by promoting dorsal identity [6-8]. The first two steps are thought to occur early in development, at the onset of zygotic transcription, whereas Spemann's organiser operates at a later stage, during gastrulation. The Nieuwkoop Centre contributes to the second signal in this model-it acts upstream of Spemann's organiser. In this review we will focus on the initial induction of the germ layers (corresponding to the first two steps of the 3SM). The inductive effects of the Spemann organiser and the secondary patterning of the germ layers (including the important role of the organiser in ectodermal regionalisation) have been reviewed elsewhere in several excellent reviews [9-13].

It is debatable to what extent the first two steps in the 3SM can be uncoupled. Nieuwkoop himself initially favoured a model whereby a single mesendoderm inducer is released in a graded fashion-high levels dorsally and low levels ventrally. However, experiments using irradiation of amphibian embryos with ultraviolet (UV) light 
pointed towards two independent signals mediating mesendoderm induction and dorsal specification: mesendoderm induction was generally unaffected in such embryos, but they displayed dorsoanterior defects suggesting that only the second signal of the 3SM was affected [14-16].

\section{Secreted factors as candidate mesendoderm inducers}

Nieuwkoop's finding that mesoderm formation depends on an inductive event suggests that it is mediated by (an) extracellular factor(s) that is secreted from vegetal cells at the blastula stage. Since the late 1980s, several candidates for the first and second signal have been identified and characterised.

\section{Fibroblast growth factors}

The first purified protein shown to induce mesoderm in amphibian animal cap tissue was basic fibroblast growth factor (bFGF) [17]. These experiments were performed using embryos of the African claw-toed frog Xenopus laevis. Shortly thereafter the first Xenopus fgf gene, bfgf, was cloned and the protein shown to be present at biologically active levels in the oocyte [18]. Since then multiple studies demonstrated mesoderm-inducing activity for FGFs and for many of its downstream signal transducers in frog [19-22], fish [23], chick [24] and mouse embryos [25]. Blocking FGF function in these embryos leads to mesodermal defects of varying degrees [19, 20, 22, 24, 26, 27].

Despite this overwhelming evidence for an important role in mesoderm induction, FGFs alone are unlikely to represent Nieuwkoop's inducer of mesoderm and endoderm. First, there is no evidence for the induction of endoderm by FGFs; second, $f g f$ mRNA is expressed in the marginal zone at early gastrula stages, in the prospective mesoderm of the frog embryo, rather than in vegetal cells $[28,29]$; and third, mesoderm is affected, but never completely eliminated in embryos with loss of FGF signalling function, suggesting that other factors at least partially compensate for the lack of FGFs. In zebrafish, FGFs were found to regulate $\mathrm{DV}$ patterning of the mesoderm rather than its induction, i.e., the third signal of the 3SM rather than the second $[30,31]$. A role for FGFs in DV patterning has recently also been suggested in Xenopus [32].

Several studies in frog and fish embryos proposed that, rather than being instructive inducers of mesodermal fate, FGFs function as competence factors that are required for the cellular response to another group of mesendoderm inducers, the transforming growth factor $\beta$ s (TGF $\beta$ s) [33-
37]. It has also been proposed that FGFs act secondarily to set apart the mesoderm from the TGF $\beta$-induced mesendoderm [38]. Taken together, it is clear that FGF signalling plays an important role in mesoderm formation, but it is not sufficient for germ layer formation on its own.

\section{Activin}

Around the time when FGFs were discovered as potential mesoderm inducers, TGF $\beta$ s were also found to induce mesoderm [33]. The first TGF $\beta$ factor coming into play was Activin A [39-41]. Activin, in addition to being able to induce a secondary axis [42], can induce a range of different DV mesodermal cell fates in a dose-dependent manner, consistent with the graded mesoderm inducer initially proposed by Nieuwkoop (see above) [42, 43]. Unlike FGFs, Activin also induces endoderm [39, 44, 45]. Activin was also shown to function as a mesendoderm inducer in chick and zebrafish [46, 47]. However, doubts about Activin's candidacy as the primary mesendoderm inducer were raised (1) by the failure of the Activin inhibitor Follistatin to interfere with mesoderm induction in frog embryos [48] (but see [49]) and (2) by the relatively mild phenotype of mouse embryos with disrupted Activin genes which suggested that this factor is not endogenously required for mesendoderm formation [50]. Nonetheless reducing levels of Activin using morpholino antisense nucleotides was shown to affect mesoderm formation to at least some extent in the frog embryo more recently [51, 52].

Attempts to interfere with Activin signalling downstream of the ligand-for example by inhibiting Activin receptor function-often resulted in much stronger defects of mesendoderm formation compared to experimental removal of the ligand itself [53]. The most likely reason for this effect is that other TGF $\beta$ ligands, which may also be involved in mesendoderm formation, signal via the same receptor pathway.

\section{Vg1}

One of these ligands is $\mathrm{Vg} 1$, which was discovered as a vegetally localised mRNA in the Xenopus embryo. In fact, this factor initially attracted interest as a model for mRNA localisation in oocytes [54]. Like other TGF $\beta s, \mathrm{Vg} 1$ is produced as a precursor peptide that needs to be cleaved and dimerise to become active. Somewhat perplexingly, although the $\mathrm{Vg} 1$ precursor was found to be abundant in early embryos, its mature form could not be detected. Furthermore injection of wild-type $V g 1 \mathrm{mRNA}$ failed to produce the axial duplications expected for a bona fide mesendoderm inducer like Activin, and only synthetic constructs in which the prepro-region (the N-terminal 
domain of the unprocessed polypeptide) of bone morphogenetic proteins 2 or 4 (BMP2/4) was fused to the core domain of mature $\mathrm{Vg} 1$ resulted in Activin-like effects [55, 56]. These results suggested that the conversion of $\mathrm{Vg} 1$ into its active form is highly inefficient, and that only tiny amounts of the active protein are present in the developing embryo. This could either mean that active Vg1 is so potent that its levels need to be kept extremely low, or that Vg1 is not the endogenous mesendoderm inducer.

Recently the Heasman lab was able to resolve the conundrum of the seemingly inactive $\mathrm{Vg} 1$ by demonstrating - using antisense depletion in Xenopus - that Vg1 is indeed essential for (dorsal) mesoderm formation. They were also able to show that the protein encoded by a second $V g l$ gene with a proline $\rightarrow$ serine substitution in its prodomain was much more efficiently processed than the original Vg1 and is therefore biologically active [57]. This study explains the effects obtained previously with a dominant-negative variant of $\mathrm{Vg} 1$ : apparently this dominant-negative simultaneously antagonised both versions of $\mathrm{Vg} 1$, resulting in severe defects in mesoderm and endoderm formation [58].

$\mathrm{Vg} 1$ in chick and its zebrafish orthologue Dvr1 are also expressed early in development and possess mesoderminducing activity [59-61]. Yet morpholino-mediated knockdown of Dvr1 in zebrafish embryos affected asymmetric development along the left-right axis, but not mesoderm formation as such [62]. In the mouse embryo, the $\mathrm{Vg} 1$ orthologue Gdf1 appears to synergise with its close relative Gdf3 since $G d f 1^{-1-} ; G d f 3^{-I-}$ double mutants are more severely affected than either single mutant, with distinctive defects in mesoderm and endoderm formation [63].

A close relative of $\mathrm{Vg} 1$, Derrière (orthologue of mammalian $G d f 3$ ), was found to be expressed in the future endoderm and mesoderm at late blastula stages of Xenopus development. Gain- and loss-of-function experiments with Derrière pointed towards a role in the induction of the posterior mesendoderm [64]. Thus, both Activins and Vg1/ Dvr1/Gdf $1 / 3$ are candidate TGF $\beta$ s involved in mesendoderm formation; however, their relevance may vary between different species and loss-of-function approaches have only partially substantiated a role for these factors as endogenous mesendoderm inducers.

\section{Nodals}

Genetic loss-of-function studies in mouse and zebrafish introduced the Nodal subfamily of TGF $\beta$ factors as mesendoderm inducers par excellence. These studies revealed that Nodal in the mouse and the Nodal-like factors Cyclops and Squint in zebrafish are strictly required for mesoderm and endoderm formation [65-67]; reviewed in
[68, 69]. Similarly inactivation of ActRIB (encoding a Nodal receptor), of genes encoding Nodal co-receptors of the EGF-CFC (epidermal growth factor-Cripto/FRL1/ Cryptic) family, and of the intracellular TGF $\beta$ signal transducers Smad2, Smad3 and Smad4 lead to severe defects in mesendoderm induction [22, 70-74].

Blocking Nodal signalling in Xenopus proved somewhat more difficult due to the large number of Nodal ligands expressed at late blastula stage [75-78]. However, simultaneous morpholino antisense knockdown of Xenopus nodal-related ( $n r$ ) 5 and 6 resulted in mesendoderm specification defects suggesting that these two may be the major players in this process, consistent with them being the earliest expressed $n r s[52,79]$.

Nodal signals are not only essential for mesendoderm induction; they also function as potent mesoderm and endoderm inducers in gain-of-function experiments [21, $75,77]$. So, are Nodals the primary mesendoderm inducers in vertebrate embryos? A subset of $\mathrm{Nodal}^{-1-}$ mouse embryos express genetic markers of the definitive posterior mesoderm and, similarly, ventroposterior mesoderm is found in squint;cyclops double mutant zebrafish embryos $[66,67]$. This suggests that, even in complete absence of Nodal signalling, there is some residual mesendoderm-inducing activity present in vertebrate embryos. No mesoderm was found in $\operatorname{Smad2}^{-1-} ; \mathrm{Smad}^{-/-}$double mutant mice indicating that this residual activity is likely mediated by other Nodal-type molecules such as Gdf1 and Gdf3, rather than the above mentioned FGFs [74].

\section{Bone morphogenetic proteins}

BMPs are also members of the TGF $\beta$ family that have anecdotally been implicated in mesoderm induction. However, compared to the Nodal subfamily, BMPs are poor mesoderm inducers [80]. BMPs signal via a different branch of the TGF $\beta$ pathway that involves Smad1 and Smad5, rather than Smad2 and Smad3, and it is possible that their weak mesoderm-inducing activity is due to aberrant activation of the Smad2/3 branch of the pathway following non-physiological overexpression. It is now broadly accepted that a major role of BMPs is to regulate DV patterning of the mesoderm, i.e., the third step of the 3SM.

Thus, the TGF $\beta$ signalling pathway is crucial in mesendoderm induction. The concentration effect of the different ligands (Nodal/Activin/ $\mathrm{Vg} 1$ ) results in the different responses (mesoderm/endoderm). However, the relative importance of each ligand may differ between different vertebrate species, and it remains to be established whether they simply function in an additive fashion, or whether they exert qualitatively different effects. FGFs seem to function by establishing the competence for 
mesoderm induction by TGF $\beta$ signals, rather than by instructing mesodermal fates themselves.

\section{Maternal Wnt/ $\beta$-catenin and the establishment of dorsal identity}

The first indication that signalling factors of the Wnt family could be involved in inducing the 'Nieuwkoop Centre' came from early overexpression studies in Xenopus where injection of Wnt mRNAs into ventro-vegetal blastomeres of the early embryo frequently resulted in complete axial duplications highly reminiscent of the Spemann organiser grafting experiment $[81,82]$. In fact, this 'axis induction essay' played a key role in establishing the canonical Wnt signalling pathway in vertebrates in the 1990s [83-87].

As mentioned above, Nieuwkoop Centre induction is sensitive to UV light such that irradiated embryos develop lacking dorsal characteristics. Fertilisation of the amphibian egg triggers a rotation of the egg cortex relative to its cytoplasm [15], and UV irradiation was shown to block this cortical rotation. The cellular target affected by UV light is a dense array of microtubules in the vegetal cortex of the egg [88], suggesting that maternal determinants that are initially found at the vegetal pole of the egg become actively translocated to the dorsal side by cortical rotation. Injection of Wnt mRNA was shown to rescue the effects of UV light; however, the first true link between the Wnt signalling pathway and axis determination came from the observation that $\beta$-catenin, an intracellular transducer of Wnt signals, becomes enriched in the dorsal half of the embryo and that this enrichment may involve active transport along microtubules and/or selective protein stabilisation $[89,90]$. Not only $\beta$-catenin, but also Dishevelled-an adaptor protein that mediates Wnt signalling downstream of its receptor and upstream of $\beta$-catenin - and glycogen synthase kinase 3 (GSK3) binding protein (GBP) are transported to the dorsal side [91, 92]. Simultaneously, GSK3, an intracellular antagonist of the Wnt pathway, becomes down-regulated dorsally (Fig. 2a) [93].

Whether the maternal dorsalising pathway is actually activated by a Wnt ligand has been controversial. Of the three Wnt ligands that are maternally expressed in Xenopus, Wnt8B and Wnt5A do not seem to be localised dorsally, and Wnt8B is only expressed at extremely low levels [83, 94]. Furthermore, Wnt5A and Wnt11 belong to a different class of Wnt ligands that are less efficient in activating the canonical Wnt signalling pathway and tend to stimulate an alternative pathway which affects morphogenesis and may even antagonise the canonical Wnt pathway [95, 96]. Genetic mutants of Wnt5A and Wnt11 in zebrafish and mouse also support a role for these factors in regulating morphogenesis rather than early DV patterning [97-99]. Moreover, inhibitors that block Wnt signalling extracellularly by ligand sequestration or by antagonising the Wnt receptor complex frequently failed to affect DV axis formation [96, 100]. Taken together, these studies initially suggested that the maternal dorsalising signal may not involve a Wnt ligand, but rather depend on pathway activation at the intracellular level. However, more recently the Heasman lab found that maternal Wnt11 mRNA is indeed required and sufficient to activate the dorsalising pathway in Xenopus [101]. Wnt11 is the only Wnt ligand that shows a dorsal enrichment at cleavage stages [102], and its interaction with the maternally expressed receptor Frizzled-7 results in canonical pathway activation [103]. The axis-inducing activity of maternal Wnt11 depends on heparan sulphate proteoglycans and on FRL1, a member of the EGF-CFC co-receptor family that is also essential for Nodal signalling [101]. Since EGFCFCs were initially identified as atypical FGF receptor ligands [104], it is tempting to speculate that these factors somehow integrate multiple maternal signals that are involved in germ layer specification.

Follow-up studies revealed that both Wnt5A and Wnt11 synergise in this process and that they function as homodimers in mediating the early dorsalising signal $[105$, 106]. Furthermore, Lipoprotein receptor-related protein 6 (LRP6) is required for this signal, and the LRP6 antagonist Dickkopf 1 (Dkk1) is present as a maternal mRNA required to prevent excessive Wnt signalling at this stage $[105,107]$. Thus, the maternal dorsalising signal has many characteristics of the canonical $\mathrm{Wnt} / \beta$-catenin signalling pathway, but also several unusual features (Wnt5A/Wnt11 activating the canonical pathway; Wnts as homodimers; the involvement of FRL1).

There is now evidence that the maternal dorsalising pathway is activated more broadly than just in dorsovegetal blastomeres: studies in Xenopus indicated that the maternal Wnt/ $\beta$-catenin-dependent pathway induces neural fate in the dorsal ectoderm [108, 109]. This happens via two parallel routes: transcriptional repression of Вmp2 [108] and induction of the extracellular BMP inhibitors Chordin, Noggin and Cerberus $[109,110]$. BMP signalling promotes ventral identity in all germ layers and the interplay between BMP inhibitors dorsally and BMPs ventrally is thought to generate a BMP activity gradient that regulates DV patterning of the embryo during gastrulation-the third step of the 3SM [9, 11-13].

Thus, maternal $\mathrm{Wnt} / \beta$-catenin signalling may be active throughout the dorsal hemisphere of the Xenopus blastula, and mesendoderm induction and the establishment of dorsal identity (steps $1+2$ of the $3 \mathrm{SM}$ ) occur-at least in part-independently. In this scenario maternal $\mathrm{Wnt} / \beta$ catenin signalling on its own does not strictly qualify for Nieuwkoop's second signal, as it is not limited to the vegetal blastomeres of the embryo. It rather seems to be the 
a

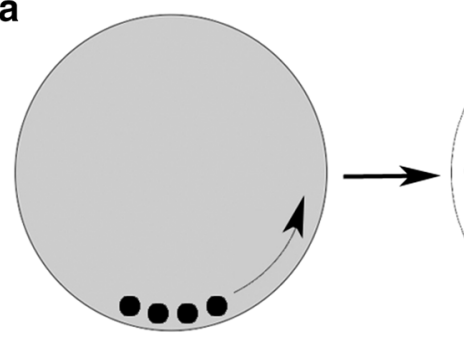

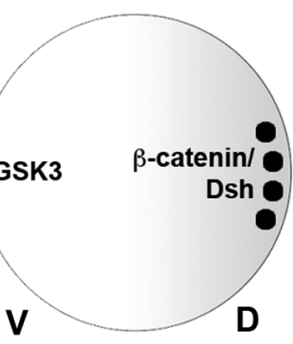

b

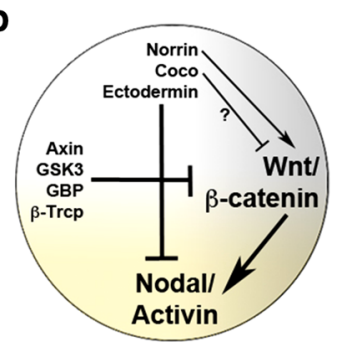

Fig. 2 The establishment of orthogonal axes in the amphibian blastula embryo. a Cortical rotation transports vegetal determinants (black dots) to the future dorsal side of the embryo leading to enrichment of $\beta$-catenin and Dishevelled (Dsh) and downregulation of GSK3 dorsally. b Wnt/ $\beta$ catenin signalling (grey gradient) specifies the dorsal side and vegetal Nodal/Activin signalling induces endoderm and mesoderm (yellow gradient). Wnt signalling is antagonised by the Wnt destruction complex involving Axin and GSK3 whereas Coco, Ectodermin and Norrin antagonise Nodal/Activin signalling in the animal hemisphere. Norrin also promotes, whereas Coco may inhibit, Wnt signalling

case that two overlapping signalling systems-Nodal/Activin and $\mathrm{Wnt} / \beta$-catenin - specify the animal-vegetal and DV axes of the embryo (Fig. 2b). These two signalling pathways are linked, as early Wnt signalling induces the Nodal genes Xenopus nodal-related 3, 5 and 6 (nr3/5/6) [72, 76-78, 111, 112]. Nr3 is an atypical Nodal ligand that antagonises TGF $\beta$ signalling [113], but nr5 and nr6 initiate a cascade of Nodal expression that is central to mesendoderm specification [79, 112]. A Wnt responsive element has been identified in the $n r l$ promoter, further supporting the idea of an interaction of the two pathways [114].

A study demonstrating that maternal $\beta$-catenin is not only active dorsally but also required all around the equatorial region of the embryo for mesoderm induction is somewhat at odds with the discussed role of this signalling pathway in dorsal specification [115]. Subtle differences in the timing of the activity of this signal may explain this finding.

\section{Dose-dependency in mesendoderm induction}

Nieuwkoop's observation that a mesendoderm inducer is released from vegetal blastomeres suggests that this inducer could function dose-dependently along the vegetalanimal axis, resulting in endoderm formation at highest levels, mesoderm formation at lower levels and ectoderm formation in the absence of the inducer (Fig. 2b). This model is supported by studies in zebrafish where graded Nodal signalling patterns the germ ring-the marginal zone of the fish embryo where all mesendodermal progenitors are located-along the vegetal-animal axis [116-118]. Evidence for a vegetal-animal gradient of Nodal/Activin signalling in amphibians is sparse and mostly indirect, based on experiments using factors that inhibit different TGF $\beta$-type factors with different efficiencies [119]. The large number of different TGF $\beta$ ligands expressed in pre- gastrula stage Xenopus embryos makes the interpretation of such experiments particularly difficult.

There is, however, fairly good evidence that Nodal/ Activin signalling in Xenopus is biased along the DV axis with higher levels specifying dorsal, and lower levels specifying ventral fates. In gain-of-function experiments, Activin (and later Nodal and $\operatorname{Vg} 1$ ) was shown to induce different mesodermal cell fates along the DV axis in a dose-dependent manner [43, 75, 120]. The Xenopus Nodal genes $n r 1, n r 2, n r 4, n r 5$ and $n r 6$ are expressed more strongly dorsally than ventrally at late blastula stage [77, 78, 111]; however, the evidence for a requirement for graded Nodal/Activin signalling in DV patterning is somewhat less conclusive, presumably due to the large number of TGF $\beta$ ligands in frogs. Injections of different doses of the synthetic Nodal inhibitor Cerberus-short (CerS) resulted in dorsoventrally biased effects with ventral mesoderm being affected at low doses and dorsal mesoderm at higher doses [111]. Similar dose-response experiments in zebrafish using Activin and the Nodal inhibitor Antivin, respectively, suggested that a gradient of these signals establish the anteroposterior (AP) axis of the fish [121]. However, these experiments are difficult to interpret, since the effects of TGF $\beta$ signalling on germ layer formation occur early, before gastrulation, whereas the AP axis is established during gastrulation involving complex interactions between the previously formed germ layers.

\section{The timing of mesendoderm induction}

Because germ layer formation takes place so early in development, one of the key questions is to which extent it is maternally controlled. Activin and $\mathrm{Vg} 1 / \mathrm{Dvr} 1$ are present as maternal factors in frog and fish embryos [46, 122]. Furthermore, the symmetry-breaking event that generates 
DV polarity is maternal, as it is triggered by sperm entry and involves the translocation of a maternal factor (possibly Wnt11) to the future dorsal side of the egg (see above). Yet, Nodals, the major class of mesendoderm-inducing factors conserved across vertebrates, are expressed zygotically in Xenopus embryos [78, 111]. However, zygotic expression of $n r 5$ and $n r 6$ begins at 256-cell stage-much earlier than that of many other genes-and is controlled by maternal $\beta$-catenin [72]. This early nr5/6 activity induces $n r l$ and $n r 2$, resulting in a cascade of Nodal expression that is at least transiently stronger on the dorsal side of the embryo [78].

Developmental signalling factors often perform different functions at different developmental stages. Thus, it is conceivable that Nodal/Activin-like factors dynamically regulate different aspects of mesendoderm induction and/or patterning in the few hours during which this process takes place in amphibians and fish. A true appreciation of the signalling dynamics of the mesendoderm-inducing factors can only come from a detailed spatiotemporal analysis of their expression or a readout of their signalling pathways.

\section{Activation of signalling pathways in vivo}

As mentioned above, Nodal/Activin-type signals are transduced via Smad2 and Smad3. Activation of these Smads is mediated via phosphorylation; thus, immunohistochemical detection of phosphorylated Smad2/3 (p-Smad2/3) provides a way of detecting Nodal pathway activation in situ. A DV gradient of p-Smad2 can be detected in the late blastula embryo of Xenopus, consistent with the stronger induction of $n r s$ on the dorsal side of the embryo by $\beta$-catenin $[123,124]$. However, this graded signal appears to be highly transient: Fauré et al. (2000) found no significant p-Smad2 before the onset of zygotic transcription [123] whereas Schohl and Fagotto (2002) observed weak activation in a supra-equatorial ring-some distance away from the maternal TGF $\beta$ ligands Activin and Vg1 [124]. During gastrulation the DV bias in Smad2 activation seems to be lost, but overall levels remain high in the endoderm [124].

In a recent study, two different approaches were used to monitor Smad2 activation in zebrafish embryos: Smad2 nuclear localisation and Smad2-Smad4 complex formation [125]. These experiments confirm the previously postulated vegetal-animal gradient of Nodal activity in zebrafish [116-118], but they also revealed that Smad2 activation is biased along the DV axis of the fish embryo, similar to what has been observed in frogs. Thus, the role of Nodal/ Activin-Smad2 signalling appears to be fairly conserved across anamniote vertebrates, contributing to both vegetalanimal and DV patterning of the mesendoderm.
Recently, this approach of monitoring Smad2 activation has been used in the zebrafish embryo to analyse the dynamics of Nodal target gene induction, revealing that not only the dose of Nodal, but also the timing and magnitude of the induction of its target genes shape the response of a tissue to this morphogen [126].

Similar to p-Smad2 serving as an indicator of Nodal/ Activin signalling, phosphorylation of mitogen-activated protein kinase (p-MAPK) can be used to visualise activation of tyrosine kinase receptors, including those that activate the branch of FGF signalling that is involved in mesoderm induction. Experimental manipulation of the FGF pathway in Xenopus embryos alters p-MAPK distribution, indicating that p-MAPK distribution represents FGF pathway activation in vivo [127]. Endogenously activated MAPK is detected in the prospective mesoderm in the marginal zone at late blastula and gastrula stages, consistent with both its proposed role as a mesodermal competence factor and the endogenous expression of FGFs at this stage of embryonic development. Interestingly, p-MAPK shows a DV bias with higher levels of expression dorsally [124, 127, 128]. A role for FGF signalling in mesodermal DV patterning has not been proposed in the frog embryo; however, it has been suggested that FGF8 induces a DV axis in zebrafish [31]. Lower levels of p-MAPK were also found in the prospective endodermal cells at the vegetal pole of the embryo, although FGFs do not appear to play an obvious role in endoderm formation $[124,129]$.

The nuclear localisation of $\beta$-catenin is indicative of canonical Wnt pathway activation. Consistent with its role as the early dorsalising signal, nuclear accumulation of $\beta$ catenin is found on the dorsal side of frog and fish embryos from early blastula stages onwards [89, 124].

Thus, the activation patterns of the signalling pathways involved in mesendoderm induction are consistent with what was postulated based on gain- and loss-offunction analyses: a maternal $\mathrm{Wnt} / \beta$-catenin signal determines the future dorsal side of the embryo whereas zygotic Nodal/Activin signalling is crucial for mesendoderm formation, and this signal also imparts DV specification as it is stronger on the dorsal side of the embryo. Simultaneously, FGF is important for the induction of the mesoderm, and this signal may also be dorsoventrally biased. FGF, Nodal/Activin and Wnt signalling are linked at multiple levels: as mentioned above, $\beta$-catenin induces the expression of Nodal ligands on the dorsal side of the embryo [72, 78], and a recent study revealed that FGF-MAPK signalling leads to $\mathrm{N}$-terminal phosphorylation of the tumour suppressor protein p53 which subsequently interacts with Smads, thereby promoting Nodal/Activin signalling [130]. 


\section{Specification of the ectoderm: Nodal, FGF and Wnt inhibitors restrict mesendoderm- inducing signals}

Cell fate decisions in developing embryos are typically regulated by a finely tuned interplay between inducing signals and their inhibitors. Thus, it is not surprising that inhibitors also control the signals that underlie the first step of cellular specification in embryos.

\section{TGF $\beta$ antagonists}

The Cerberus/Dan gene family encodes multifunctional inhibitors of BMP, Nodal/Activin and Wnt signalling. One member of this family, Coco, is expressed maternally in Xenopus embryos with higher levels of expression throughout the animal hemisphere [131]. Antisense-mediated knockdown of maternal Coco mRNA resulted in an expansion of endoderm at the expense of mesoderm, and this effect could be rescued to differing degrees by eliminating either Activin or nr5 and nr6 [52]. These results not only suggest that the role of maternal Coco is to limit endoderm induction by high levels of Nodal/Activin signalling, they also provide evidence that Activin, nr5 and nr6 function redundantly in endoderm induction. Interestingly, the expansion of endoderm is much more noticeable on the dorsal side of the embryo, in line with the idea of a DV gradient of Nodal activity (see above).

It remains to be established whether Coco also antagonises the dorsalising Wnt5A/11 signal that establishes the 'Nieuwkoop Centre'; however, the extent of Spemann's organiser is reduced in Coco knockdown embryos due to the overall reduction in mesoderm formation, complicating the assessment of 'dorsalisation' in such embryos. The reduction of organiser activity explains the lack of anterior specification in Coco-deficient embryos-which lack heads-at later stages [52]. It would be interesting to analyse whether embryos show increased nuclear enrichment of $\beta$-catenin following Coco knockdown.

A recent study revealed that the Xenopus orthologue of the human disease gene Norrin is maternally expressed in animal blastomeres and that its overexpression results in an expansion of the neural plate (= dorsal ectoderm) [132]. It had previously been shown that Norrin activates canonical Wnt signalling by interacting with the Wnt receptor Frizzled4; thus, a dorsalised phenotype upon Norrin overexpression was not too surprising [133]. However, the authors discovered an additional function of Norrin in inhibiting Nodal/Activin and BMP signalling through direct binding and sequestration of these ligands. Thus, Norrin functions in a similar manner to Coco with respect to TGF $\beta$ signalling, but in an opposite manner with respect to Wnt signalling [132].
Another factor that is expressed maternally throughout the animal hemisphere of the Xenopus embryo is Ectodermin, a RING-type ubiquitin ligase that targets Smad4 for proteasomal degradation [134]. Weak expression, with a dorsal bias, is seen at gastrula stages; however, Ectodermin expression is lost after gastrulation. Smad4 is an essential co-factor for both $\operatorname{Smad} 2 / 3$ and Smad1/5; thus, Ectodermin antagonises both Nodal/Activin and BMP signalling. Antisense-mediated knockdown of maternal Ectodermin reveals essential functions in both pathways, as both endoderm and non-neural ectoderm expand at the cost of mesoderm and neuroectoderm, respectively. Taken together both extracellular and intracellular inhibitors of TGF $\beta$ signalling are required to antagonise mesendoderm induction and thereby protect the prospective ectoderm.

\section{FGF antagonists}

No specific secreted FGF antagonists have been identified to date; however, FGF signalling is limited through a negative feedback loop that involves auto-induction of intracellular FGF inhibitors of the Sprouty and Spred families. In Xenopus these two families appear to differentially regulate different branches of the FGF signalling pathway: gain- and loss-of-function experiments targeting Sprouty1 and Sprouty2 revealed their role in modulating the $\mathrm{FGF}-\mathrm{Ca}^{2+}$-PKC $\delta$ signalling pathway and gastrulation movements whereas a comparable set of experiments targeting Spred1 and Spred2 indicated that they antagonise MAPK activation and mesoderm specification [135]. Sprouty and Spred genes are zygotically induced by FGF signalling; thus, their role is to limit the signal after its onset, rather than excluding FGF signalling from a prespecified domain.

\section{Wnt antagonists}

The maternal Wnt/ $\beta$-catenin signal that defines the dorsal half of the embryo is restricted by both extracellular and intracellular antagonists. The Heasman laboratory found that Dickkopf1 (Dkk1), an antagonist of the Wnt receptor complex, is present as a maternal mRNA in Xenopus oocytes and that its depletion using antisense oligonucleotides results in profound patterning and gastrulation defects [105]. However, this study does not explain why injection of exogenous Dkk1 mRNA into early blastula stage embryos leads to dorsoanteriorised embryos, consistent with an inhibition of Wnt signalling after the onset of zygotic transcription rather than ventralisation [136].

The maternal $\mathrm{Wnt} / \beta$-catenin signal is also antagonised by a number of intracellular pathway inhibitors. GSK3 is part of a protein complex that targets $\beta$-catenin for destruction by the proteasome and gain- and loss-of- 
function experiments demonstrated an essential role in regulating primary DV patterning of the frog embryo [84, 86]. The finding that lithium ions $\left(\mathrm{Li}^{+}\right)$inhibit GSK3 for the first time provided an explanation as to why $\mathrm{Li}^{+}$-treated Xenopus embryos become hyperdorsalised [137]. Subsequently other components of this $\beta$-catenin destruction complex were also found to affect embryonic axis formation: the adaptor proteins Axin and Axil, the GSK3 inhibitor GBP (GSK3 binding protein) and the ubiquitin ligase $\beta$-Trcp all inhibit $\mathrm{Wnt} / \beta$-catenin and antagonise Nieuwkoop Centre formation [87, 138-144]. Moreover, GSK3 protein levels are specifically downregulated on the dorsal side of the embryo following cortical rotation [93]. This finding suggests that Dsh and/or GBP, or an as yet unknown GSK3 antagonist, is moved towards the dorsal side of the embryo, most likely via the microtubule network mentioned above.

Taken together, all three major signalling pathways that govern the early steps of germ layer specification are antagonised at different levels. FGFs are controlled via a negative feedback loop involving Spreds; Wnt/ $\beta$-catenin signalling is negatively regulated by maternal Dkk1, Norrin and by various components of the $\beta$-catenin destruction complex; and Nodal/Activin signalling is restricted to the vegetal hemisphere by maternal factors in the animal hemisphere-Coco, Norrin and Ectodermin (Fig. 2b).

\section{Transcription factors in germ layer specification}

\section{VegT}

In the fruit fly Drosophila, a classical model organism for developmental geneticists, embryonic axis formation is regulated by maternal mRNAs that are differentially localised in the oocyte. In 1996, maternal transcripts of the Xenopus T-domain transcription factor VegT (also known as Antipodean, Brat, Xombi or tbx6) were found to localise to the oocyte's vegetal cortex [21, 145-147]. Ectopic expression of VegT results in induction of mesodermal [21, $145,146]$ as well as endodermal markers [147] and even ectopic bottle cells-dorsovegetal cells that appear at the onset of gastrulation and mark the initial site of tissue internalisation [148]. Importantly, antisense depletion of maternal VegT mRNA resulted in embryos that lacked endoderm, showed a reduction and vegetal shift of the mesoderm and displayed an expansion of the ectoderm into the equatorial region, suggesting that maternal VegT is a key determinant in germ layer specification [107, 149]. In support of this, VegT-depleted vegetal poles could not induce mesoderm in co-cultured blastula stage animal cap tissue [149].
After the onset of zygotic transcription there is a DV wave of $V e g T$ expression in the equatorial region of the blastula, and ectopic expression can be induced by eFGF (but not bFGF), Nodal/Activin signalling and by itself at this stage $[21,145,146]$. Thus, maternal VegT not only initiates a cascade of mesendoderm induction (Fig. 3), but also maintains and augments its own expression via positive feedback mechanisms. It has been suggested that maternal VegT mRNA is present in a vegetal-animal gradient with high doses of this factor inducing endoderm and lower doses inducing mesoderm [150].

$\mathrm{VegT}$ is required for the expression of FGFs and of the TGF $\beta$ s nr1/2/4/5/6 and Derrière, and overexpression of each of these TGF $\beta$ s in VegT-depleted embryos rescues different aspects of mesoderm and endoderm induction, indicating that VegT functions in a superordinate fashion with respect to these pathways [78, 107, 111, 112]. As mentioned previously, the induction of $n r 5$ and $n r 6$ occurs earlier than the onset of zygotic transcription of most other genes [24, 151], but VegT plays an ongoing role in mesodermal differentiation as it is required for the formation of the paraxial mesoderm which gives rise to the somites and muscle at later stages [152].

\section{Hepatocyte nuclear factors}

Another group of transcription factors potentially involved in mesendoderm specification in Xenopus are the Hepatocyte nuclear factor (Hnf) family. Hnf4 is present as a

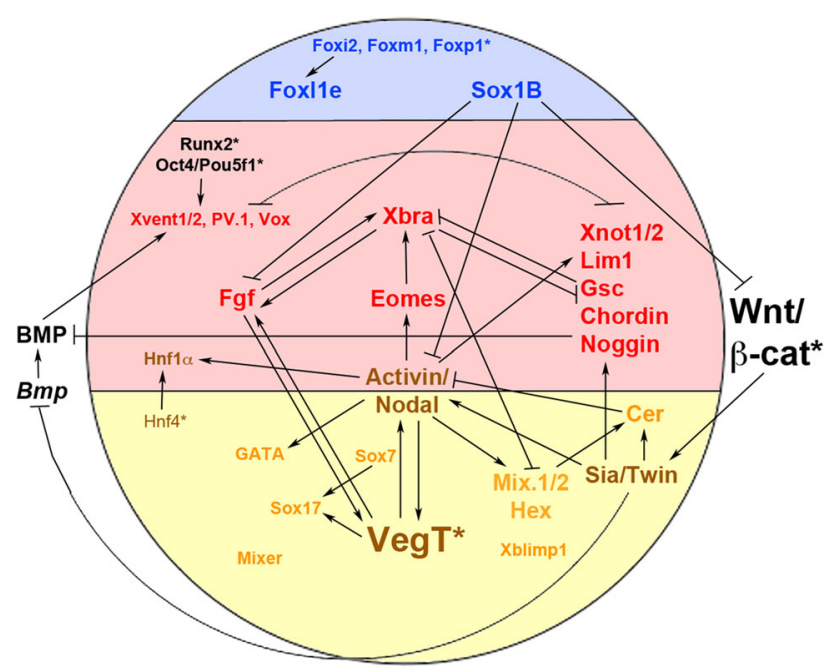

Fig. 3 The gene regulatory network of mesendoderm formation. Schematic diagram of an amphibian blastula (dorsal to the right) showing a subset of the genetic interactions involved in germ layer formation. Genes expressed in the ectoderm are shown in blue, mesoderm in red, endoderm in yellow/orange; genes expressed in both endoderm and mesoderm are shown in brown; more generally expressed genes in black. Key maternal factors are indicated with an asterisk 
maternal protein that is enriched in the vegetal half of the oocyte and has been shown to activate $H n f l \alpha$, a marker of definitive mesendodermal lineages (liver, gall bladder, gut, pronephros etc. [153]). Interestingly, the Hnf4 binding site in the $H n f l \alpha$ promoter is in close proximity to an Activinresponse element (ARE, binds Smad2/3), suggesting that Activin/Nodal signalling and maternal Hnf4 cooperate in activating mesendodermal gene expression [44]. Experiments using a dominant-negative form of Hnf1 $\beta$ suggest that Hnf1 activity is required for mesendoderm formation. This activity depends on Nodal/Activin, but not on FGF, signalling as (1) ectopic expression of Hnf $1 \beta$ alone does not result in mesoderm induction and (2) the dominantnegative construct blocks Vg1-mediated, but not eFGFmediated, mesendoderm induction in animal cap explants [154].

\section{Transcriptional targets of the maternal $\beta$-catenin signal}

Besides inducing $n r 5$ and $n r 6$ and repressing bmp4 (see above), maternal $\beta$-catenin has several other target genes that encode transcription factors. The first gene proposed to be a marker of the 'Nieuwkoop Centre' was the homeobox gene siamois (sia), which is detected shortly after the onset of zygotic transcription in dorsovegetal cells of the blastula embryo [110, 155]. Sia, a potent inducer of ectopic embryonic axes [156], is induced by maternal $\mathrm{Wnt} / \beta$ catenin signalling independently from mesoderm formation (Fig. 3) [157-160]. Sia functions redundantly with its close relative, twin, which is also induced directly by Wnt signalling and also induces secondary embryonic axes [161]. Sia and Twin proteins form both homodimers and heterodimers and their simultaneous (but not individual) knockdown results in disrupted organiser and axis formation [162].

One of the direct transcriptional targets of Sia/Twin is cerberus, encoding a multifunctional growth factor inhibitor related to Coco. Cerberus is expressed in the anterior endoderm of Spemann's organiser and promotes head formation via inhibiting the posteriorising/ventralising Nodal, BMP and Wnt pathways during gastrulation [163165]. As Sia and Twin also repress bmp4 expression, their function in dorsalising the embryo is likely to be twofold: (1) they repress the transcription of ventralising bmps and (2) they induce dorsalising organiser factors such as cerberus and chordin [155].

The bozozok/dharma/nieuwkoid (boz) gene is the functional equivalent of sia in the zebrafish embryo, although their sequences are too divergent to be true orthologues [166]. As for sia in the frog, boz is induced by maternal Wnt/ $\beta$-catenin activity on the dorsal side of the embryo, and it is required to repress the expression of $b m p 2 b$ dorsally, in the prospective organiser region [167, 168]. The boz promoter has several high-affinity binding sites for Wnt transducers of the TCF/LEF family, emphasising that it is a likely direct target of the dorsalising maternal pathway [168]. Recently, it was demonstrated that the Boz protein is a target of the E3 ubiquitin ligase Lnx-1 (Ligand of Numb protein-X-like). Depletion of Lnx-1 results in increased Boz levels and strongly dorsalised embryos, indicating that the proteolytic turnover of Boz plays a central regulatory function in DV axis formation in fish [169].

\section{Transcription factors in mesoderm formation: Brachyury}

The first gene found to be essential for mesoderm formation was Brachyury (Short Tail, T) in the mouse. Brachyury is a naturally occurring mutation that affects tail length and sacral vertebrae in heterozygous mice [170]. Homozygous animals die during embryogenesis due to severe defects in mesoderm formation and morphogenesis [171-173]. The cloning of the $T$ locus was one of the first examples of positional gene cloning [174], and its gene product was found to be expressed in the primitive streak, the prospective mesoderm and the notochord of the early mouse embryo [175]. The Xenopus orthologue of Brachyury, bra (also known as Xbra), was identified shortly afterwards and was detected equatorially - as expected for a mesodermal determinant-where it is induced by Nodal/ Activin signalling [176, 177]. Subsequently Brachyury's DNA-binding activity was discovered [178], it was revealed that it functions as a tissue-specific transcription factor [179], and overexpression of bra in Xenopus resulted in widespread ectopic induction of mesoderm [180]. Conversely, injection of mRNA encoding a dominant-negative version of bra interfered with mesoderm formation in both frog and fish embryos, to some extent replicating the mutant phenotype in the mouse [181]. Everything pointed towards a key role for Brachyury in mesoderm formation.

In follow-up studies bra was shown to be induced by FGF signals [19, 182, 183] and, conversely, bra induced expression of efg $f$ and required a functional FGF signalling pathway in order to induce mesoderm [184]. Thus bra and the mesodermal competence signal FGF activate each other in a positive feedback loop (Fig. 3). Bra is induced by low levels, but repressed by high levels of Activin, and it has been proposed that this dose-dependency of bra induction provides a read-out of the Nodal/Activin gradient that patterns the mesoderm [183, 185-187].

A screen for transcriptional targets of bra led to the identification of five genes: bixl, wnt11, egrl, btgl and BIG3/1A11 [188]. Bixl, a paired box-homeodomain transcription factor, is a direct target of bra and induces ventral 
mesoderm and endoderm following mis-expression at low and high levels, respectively [189]. Wnt11 activates a $\beta$ catenin-independent, non-canonical Wnt pathway that orchestrates gastrulation movements [190]. Egrl encodes a zinc finger transcription factor expressed throughout the mesoderm in a DV wave. The induction of egrl by bra is likely to be indirectly mediated via the FGF-MAPK signalling pathway [191].

\section{Transcription factors in mesoderm formation: Eomesodermin}

Yet another T-box gene called Eomesodermin (Eomes), whose expression precedes that of bra, was identified by Sir John Gurdon's laboratory in 1996. Eomes is induced by TGF $\beta$ s (but not eFGF) and its overexpression in animal cap tissue results in induction of a broad range of mesodermal markers, including bra [192]. This places Eomes upstream of $b r a$ in the mesoderm induction cascade. The Eomes promoter contains an ARE indicating that its expression is a direct result of TGF $\beta$-mediated mesendoderm induction. It also contains a repressor element that blocks Eomes expression in the endoderm [192, 193].

Targeted disruption of the Eomes locus in the mouse revealed that this gene is also essential for mesoderm formation in mammals [194]. In zebrafish Eomes is expressed maternally underlining its importance in the earliest steps of embryo patterning; gain- and loss-of-function experiments suggested a slightly different role for Eomes in establishing the organiser (dorsal mesoderm) [195]. In addition Eomes is also required for endoderm formation in the fish embryo [196].

\section{Transcription factors specifying the dorsal mesoderm}

There are a large number of transcription factors that are differentially expressed in DV subdivisions of the mesoderm. The dorsal-most mesoderm (Spemann's organiser) expresses the homeobox genes goosecoid (gsc), not1, not2, Xenopus iroquois 1 (irol), the LIM/homeobox gene lim 1 and the winged-helix genes pintallavis/foxA $4 a$ and $H n f 3 \beta /$ Foxa2 [197-203]. The homeobox genes vent1, vent2, PV.1, vox, the basic helix-loop-helix gene $m y o D$ and the zinc finger gene Xpo are expressed in a complementary fashion in the ventrolateral mesoderm [204-209]. The myogenic factor myf5 is expressed in the paraxial mesoderm, overlapping with many of the ventrolaterally expressed genes, but excluding the dorsal-most region [210].

Gsc represses bra, and it has been suggested that this is how different Activin doses are translated into different DV gene expression domains in the mesoderm [183]. Gsc, not1/2, lim 1 and pintallavis are all induced by Activin, but only not1/2's expression also depends on FGF signalling (but see [35, 198]). Consistently an ARE was identified in liml's first intron [211]. Loss-of-function experiments in frog, fish and mouse embryos have revealed that most of the dorsally expressed transcription factors are required at least to some extent for dorsal mesoderm formation [73, 212-216]. Importantly mice lacking Liml function are headless [217] and those lacking Foxa2 fail to form an organiser and a notochord $[218,219]$ suggesting a key role for Lim1 in head development and a role for Foxa2 dorsal specification. However, mice with a targeted mutation in Gsc gastrulate normally and instead display craniofacial defects and malformations of the rib cage, suggesting that Gsc is not essential for organiser function-at least in mammals [220, 221]. Yet, depletion of $g s c$ mRNA in frog embryos results in anterior defects, suggesting differential requirements for this factor in rodents and amphibians [216].

A recent study in Xenopus found Foxa2 expression throughout the endoderm at late blastula stages, and overexpression experiments using different gain-of-function and antimorphic constructs suggested that endodermal Foxa 2 antagonises dorsal mesoderm and axis formation. The authors propose that this parallels a requirement for this gene in the extraembryonic endoderm in the mouse and that a conserved role of Foxa 2 is to limit ectopic mesoderm formation [222, 223].

\section{Transcription factors specifying the ventrolateral mesoderm}

The first factor found to be expressed in the ventral mesoderm at the onset of gastrulation in Xenopus was the basic helix-loop-helix transcription factor MyoD [204]. In mouse MyoD was initially identified as a main regulator of muscle formation that commits cells to the myogenic lineage upon transfection [224]. Xenopus myoD is expressed throughout the ventral mesoderm, including non-myogenic mesoderm, at the onset of gastrulation, suggesting that transient expression of this factor is not sufficient to induce myogenesis and that it is a more general response to ventral mesoderm induction [204].

Xenopus myf5 is a relative of $m y o D$ as it also encodes a basic helix-loop-helix transcription factor that is able to convert mammalian cells into muscle upon transfection [225]. Unlike myoD, myf5 is expressed only in the paraxial mesoderm (presumptive somites) lateral of the organiser region [210].

The homeobox genes vent $1 / 2, P V .1$ and vox are all expressed in the ventrolateral mesoderm; they are induced by ventralising BMP signalling; and they induce BMPs, antagonise organiser genes and ventralise embryos upon overexpression [32, 205-208]. Injections of dominant- 
negative forms of these factors into ventral blastomeres of Xenopus embryos frequently result in the induction of a secondary organiser and, subsequently, body axis duplication [226, 227].

The vent and vox genes are also found in zebrafish where they are called vega2 and vegal, respectively. They exert the same function as in frogs: (1) induction of ventral fates and (2) antagonism of the organiser by establishing a crossrepressive loop with boz [228, 229]. Another homeobox gene, ved, and the zebrafish even skipped-like gene evel also function in this group of ventralising factors [230, 231].

Zebrafish maternal and zygotic spiel ohne grenzen (MZspg) mutants display a profound expansion of dorsal at the expense of ventral tissues at the onset of gastrulation [232]. The mammalian orthologue of the spg gene is Oct4/ Pou5f1, a known pluripotency or 'stem cell' factor, and vox is one of zebrafish Pou5f1's direct transcriptional targets. Furthermore, Pou5f1 negatively controls $f g f 8$ expression [233]. These findings demonstrate that the acquisition of ventral identity also involves an active early (maternal) step.

\section{Transcription factors in endoderm formation: the Mix/Mixer/Milk family}

Depletion of maternal VegT from Xenopus oocytes demonstrated that this factor is strictly required for both mesoderm and endoderm formation (see above), raising the question as to which factors mediate the specification of the endoderm.

The first transcription factor found to be expressed in the endoderm (although not exclusively, as it is also expressed in the mesoderm) of the Xenopus embryo was the homeodomain protein Mix.1 which is directly induced by TGF $\beta$ and FGF signalling in animal cap explants. In fact, this was the first study suggesting that the signals inducing mesoderm and endoderm may be similar [234]. Interestingly Mix.1 can heterodimerise with Sia and may antagonise Sia function in embryonic axis induction, although the functional relevance of this is somewhat unclear [235]. Mix.1 also suppresses bra suggesting that high levels of Mix.1 may promote endoderm at the expense of mesoderm induction [183].

Lemaire et al. reconciled these observations by demonstrating that Mix.1 and bra mutually repress each other and that Mix.1 synergises with Sia in inducing the endodermal marker genes cerberus, endodermin $(e d d)$ and Xlhbox8 in animal caps [163, 236-238]. Importantly, blocking Mix.1 function using a dominant-negative construct resulted in a loss of endoderm differentiation [214, 238, 239]. Another factor cooperating with Mix.1 is the zinc finger transcription factor blimp1; these two factors synergise in blocking trunk mesoderm and promoting anterior endoderm formation [240]. Collectively these experiments provided support for the idea that Mix.1 is a key factor in specifying the endoderm.

Several mix.1-related genes with very similar characteristics were subsequently identified: mix.2, bix $2 / m i l k$, mixer/mix.3, bix1/mix.4, bix3 and bix4 [241, 242]. Of those four genes, the expression of mixer is confined to the endoderm, suggesting a specific role in its induction [242], whereas bixl induces both endoderm and ventral mesoderm in overexpression experiments [189]. Bix4 is the only maternally expressed gene of this group (in both mesoderm and endoderm). Its subsequent zygotic induction requires maternal VegT, and it rescues endoderm formation, but not mesoderm induction, in VegT-depleted embryos, indicating that it plays an essential role in endoderm formation downstream of VegT [243].

The zebrafish bonnie and clyde (bon) locus encodes a zebrafish Mix-related transcription factor, and bon mutants display a severe reduction of endodermal precursor cells [244]. Another Mix-like factor, Mezzo, is acting in parallel with Bon in fish, highlighting the importance of this gene family in endoderm formation [245]. The promoter of mix. 2 has a well-characterised ARE, confirming that mix genes are a direct response to mesendoderm-inducing Nodal/Activin signalling [246].

\section{Transcription factors in endoderm formation: the Sox family}

The high mobility group (HMG) transcription factors Sox $17 \alpha$ and Sox $17 \beta$ are two of the more specific markers of endoderm in Xenopus embryos. Their overexpression in animal cap explants induces markers of the definitive endoderm and this induction can be blocked by a dominant-negative Sox 17 protein. The dominant-negative also inhibits the induction of endoderm by activin, indicating that Sox $17 \alpha / \beta$ function downstream of this inducer, and it blocks endoderm formation in whole embryos [45]. Experiments using specific VegT and Nodal inhibitors suggested that Sox $17 \alpha$ is induced by both factors, but in successive time windows: the initial induction of Sox $17 \alpha$ depends on VegT, but not on Nodal signalling, whereas the maintenance of Sox $17 \alpha$ expression during gastrulation requires both VegT and Nodal [247].

Interestingly Sox $17 \alpha / \beta$ antagonise the dorsalising maternal $\mathrm{Wnt} / \beta$-catenin signal upstream of sia induction. This inhibition is likely due to a physical association of the Sox 17 proteins with $\beta$-catenin [248]. It has been suggested that, by interacting with $\beta$-catenin, the SoxF subfamily of transcription factors (that includes Sox 17) establishes at least some aspects of endodermal gene expression [249]. 
Another Sox gene of the SoxF subfamily that was found to be maternally expressed and localised to the vegetal hemisphere in Xenopus, Sox7, functions immediately downstream of VegT where it induces transcription of $\mathrm{nrll}$ $2 / 4 / 5 / 6$, mixer and Sox $17 \beta$. The $n r 5$ promoter contains a binding site that can be occupied alternatively by Sox3 or Sox7, but not by Sox17 [250]. Sox3, a member of the SoxB1 subfamily, is expressed in the animal hemisphere of the embryo where it antagonises $n r 5$ induction [251], suggesting that the animal-vegetal axis of the embryo is specified by the complementary expression of SoxB 1 and Sox $F$ genes that repress and promote mesendoderm formation, respectively [252].

\section{Transcription factors in endoderm formation: GATA and Hex}

Zinc finger transcription factors of the GATA family are also involved in endoderm formation in the frog. GATA4, GATA5 and GATA6 are all induced by Nodal/Activin signalling and they induce various endodermal marker genes in overexpression assay [253]. Consistently zebrafish GATA5, encoded by the faust locus, is required for endoderm formation in fish [254].

The homeobox gene hex was discovered as a marker of the anterior endoderm, the tissue that also expresses the multifunctional BMP/Nodal and Wnt inhibitor Cerberus. Intriguingly, hex-expressing cells originate in the blastocoel floor and move towards the anterior side at the onset of gastrulation. Ectopic expression of hex on the ventral side of a frog embryo resulted in axis duplication although the organiser markers gsc and chordin are downregulated by overexpression of hex on the dorsal side [255]. However, hex does induce cerberus, and blocking hex function using a dominant-negative construct inverts this scenario by repressing cerberus and upregulating gsc and chordin. Thus, hex promotes anterior endoderm at the expense of organiser formation [256]. More recently, it was shown that Hex boosts the early dorsalising Wnt signal by inhibiting the expression of tle4, encoding a Groucho-type co-repressor that blocks Wnt target genes. Consequently, sia and $n r 3$ are upregulated in areas of hex expression. Furthermore, Hex upregulates $n r l$ and $n r 2$ expression directly [257].

How do mesoderm and endoderm become properly segregated after their initial induction? Many of the germ layer-specific transcription factors cross-repress each other, thereby stabilising this binary cell fate choice [238]. In some cases, these factors may play an even more direct role in segregating different cell populations: a recent study has revealed that the endoderm-specific factor Sox17 is required for the formation of the basement membrane that separates the gut endoderm from the mesoderm [258].

\section{Transcription factors in the ectoderm}

Traditionally ectoderm was regarded as somewhat of a blank canvas - a 'default state' that can be turned into mesoderm or endoderm via the addition of the right inducers. We have above discussed the roles of ectodermally expressed growth factor antagonists (Coco, norrin and Ectodermin) in protecting ectodermal cell fate from excessive signalling by such inducers. However, more recently factors that actively specify ectodermal cell fates have been identified.

Several Forkhead box genes are maternally expressed in Xenopus and their transcripts are localised to animal blastomeres: foxi2, foxm1 and foxp1 [259]. Foxlle (also known as Xema, Xenopus ectodermally expressed mesendoderm antagonist), a zygotically expressed foxi gene encoding an inhibitor of mesendoderm induction [260], is a direct target of Foxi2 [261]. Overexpression of foxlle results in suppression of mesendodermal identity whereas foxlle knockdown causes the opposite effect with various mesendodermal markers encroaching upon the animal hemisphere [260]. In addition foxlle is required in a cellautonomous fashion for the maintenance of ectodermal fate, as Foxlle-depleted ectoderm cells intermingle with other germ layers and subsequently differentiate according to their new positions [262].

As mentioned above, the SoxB 1 gene Sox3 is expressed in the animal hemisphere of the frog embryo where it antagonises mesendoderm formation by repressing $n r 5$ [251]. Like Sox17, Sox3 also antagonises the dorsalising early Wnt signal by directly interacting with $\beta$-catenin [248]. Similarly, the SoxB1 genes Sox3 and Sox19a/b antagonise the cascade that leads to organiser formation downstream of maternal Wnt signalling in zebrafish embryos [263]. Moreover, SoxB1 genes restrict dorsal mesoderm formation by repressing the expression of $f g f 3$ and $f g f 8$ [264]. Thus, the SoxB 1 family protects ectodermal fate (1) by antagonising mesendoderm induction by SoxFs and (2) by limiting dorsal mesoderm formation [252].

Taken together, complex networks of transcription factors regulate the formation of all germ layers. These networks contain negative and positive feedback loops that serve to stabilise cell fate decisions. It is striking that certain families of transcription factors appear to be selectively overrepresented in specific aspects of germ layer formation-the Foxi and SoxB1 families in the ectoderm, the GATA and SoxF families in the endoderm 
and the Mix homeodomain and T-box families in the mesendoderm (Fig. 3).

\section{Competence}

The idea that cell specification during embryogenesis is mediated by inductive events between tissues goes back to the very beginnings of experimental embryology. However, already at that time it was noted that a tissue receiving an inductive signal has to be competent to respond to the signal in a specific manner [265]. This concept of 'embryonic competence' persists until today and has some relevance for the induction of the germ layers.

\section{Competence for mesendoderm induction}

In 1985, Dale et al. noted that the competence for mesoderm induction in animal cap explants depends on the developmental stage of the donor embryo: animal caps dissected at blastula stage can be converted into mesoderm whereas animal caps dissected at early gastrula stage have lost this competence [266]. This loss of mesodermal competence occurs in dissociated cells and even in the presence of the protein synthesis inhibitor cycloheximide, indicating that it is a cell-autonomous process that does not require cell communication, proliferation or new protein synthesis [267]. Similarly a loss of competence for the dorsalising signal was observed during gastrulation [268].

A compellingly simple model for the loss of responsiveness to Nodal/Activin signalling was proposed by the Gurdon laboratory: translocation of the Nodal/Activin transducer Smad2 is a prerequisite for the transduction of a signal, and increased phosphorylation of $\operatorname{Smad} 2$ at a site distinct from its activation domain after the onset of zygotic transcription prevents Smad2 from being shuttled into the nucleus. Thus, the loss of competence for mesendoderm inducers of the Nodal/Activin family is due to nuclear exclusion of Smad2 [269].

A landmark study in 1997 demonstrated that the onset of zygotic transcription is accompanied by an exchange of linker histones-proteins ensuring that chromosomal DNA stays tightly wrapped around the core histones-from an oocyte-specific form, histone B4/H1M, to histone $\mathrm{H} 1$, and that this exchange is causative for the loss of mesodermal competence [270]. This was one of the first studies implicating an epigenetic mechanism in a developmental cell fate decision. More recently, a finely tuned balance of different linker histone variants was found to endow blastomeres with mesodermal competence [271].

Another histone that is differentially expressed during early embryogenesis is the core histone H3.3. Depletion of H3.3, or of the H3.3 chaperone HIRA, results in mesodermal defects; however, these are likely to emerge after mesoderm induction has occurred, as the earliest marker whose expression is affected is bra whereas earlier markers such as eomes remain unchanged [272].

Although ectodermal cells have lost the competence to form mesoderm in response to Activin/Nodal and FGF at late gastrula stages, experiments with an inducible bra constructs demonstrated that ectopic expression of this factor still converts them into mesoderm, consistent with the later function of bra in the mesoderm induction cascade [273]. A series of grafting experiments using more differentiated mesodermal tissues also indicated that germ layer identities are not fixed until the end of gastrulation [274]. Experimental expression of an activated form of Smad2 in the neuroectoderm resulted in suppression of SoxB1 genes and concomittant induction of chordin and myoD, lending further support to the plasticity of germ layer identities during gastrulation [275]. Thus, the loss of mesodermal competence can be overridden under specific circumstances.

An interesting recent study has revealed that blastula stage animal pole cells express a range of molecular markers that later on are also expressed in the neural crest, a multipotent cell population that migrates into different locations of the developing embryo and gives rise to multiple cell types. Activin treatment induces endoderm from neural crest cells, suggesting that the overlapping set of factors that is expressed in both animal cap and neural crest cells may function as a conserved set of multipotency factors that endow these cells with the competence for endoderm induction [276].

\section{Dorsoventral competence}

Shortly after the discovery of Activin it was noted that animal blastomeres exhibit a pre-pattern that determines the response to this inducer: dorsal and ventral animal blastomeres treated with the same dose of Activin develop predominantly into trunk/tail structures and ventral mesoderm, respectively [104, 277]. Dorsal competence was later shown to be induced in ventral animal blastomeres by treatment with the pharmacological Wnt activator lithium [278], and it is now clear that activin treatment of animal blastomeres simply reveals the DV pattern that is induced by the dorsalising maternal Wnt/ $\beta$-catenin signal discussed above [279]. Thus, spatial differences in competence may be caused by a pre-pattern that has been established previously, or by partially overlapping signals. Along similar lines, FGFs are now regarded as competence factors that allow mesoderm induction in response to mesendoderm inducers of the Nodal/Activin family, rather than mesoderm inducers themselves (see above) [33-35, 37, 280]. 


\section{Germ layer formation in amniotes}

Amniotes (reptiles, birds and mammals) differ from anamniotes (fish and amphibians) in that their eggs develop either in ovo or in utero. This puts certain constraints on embryonic development, with consequences for the way the germ layers are formed in these animals. Because the embryos of oviparous amniotes tend to develop over a longer time frame than those of anamniotes, and because their eggs are laid out for terrestrial development, they need a larger supply of yolk and liquid. The disproportionally large yolk found in birds and reptiles (and in monotreme mammals) imposes morphological constraints on the shape of their embryos and, consequently, on the geometry of germ layer formation [281].

\section{Germ layer formation in birds and reptiles}

At blastoderm stages, bird and reptile embryos consist of two layers: the superficial epiblast that gives rise to the embryo proper, and the hypoblast beneath it that does not contribute to the embryo itself. The beginning of gastrulation in birds is marked by a thickening of the epiblast on the presumptive posterior side ('Koller's sickle'), from which the macroscopically visible 'primitive streak' starts to extend anteriorly, towards the middle of the epiblast. During gastrulation, epiblast cells ingress through the primitive streak and insert themselves into the lower layers, thereby forming the endoderm and mesoderm of the avian embryo (Fig. 4a). Thus, the primitive streak is the equivalent of the blastopore of anamniote embryos.

There is evidence that the endoderm and the different derivatives of the mesoderm are specified by the time of their ingression through the streak: endoderm seems to originate from cells that ingress through the anterior part of the elongating streak [282], whereas mesoderm ingresses shortly thereafter with more dorsal mesoderm coming from the anterior, and more ventral mesoderm coming from the posterior streak [282, 283].

\section{TGFßs, FGFs and Wnts in birds}

The role of TGF $\beta$ s as the principal inducers of mesoderm is conserved in birds. Activin is expressed by the hypoblast at the time of mesoderm induction and exogenous Activin induces all types of mesodermal structures in isolated epiblast tissue and in chick embryos [47, 284, 285]. Exogenous Activin also induces Brachyury, which is normally expressed in the primitive streak and in early migrating mesoderm cells [179], and Gnotl, the chick orthologue of notl [286].

Chick Vg1 expression is more localised than that of Activin and is restricted to Koller's sickle. Application of Vg1 to ectopic locations in the marginal zone of the epiblast resulted in induction of complete secondary streaks, suggesting that Koller's sickle could be the functional equivalent of the 'Nieuwkoop Centre' [60, 61].

Chick Nodal is expressed in the posterior epiblast, immediately adjacent to the domain of $\mathrm{Vg} 1$ expression, and later on in the primitive streak [287-289]. Importantly, Nodal expression is induced in response to ectopic Vg1, suggesting a relay of signals whereby $\mathrm{Vg} 1$ in Koller's sickle induces Nodal in the epiblast [290]. Like Vg1, ectopic Nodal can induce a primitive streak, but only after the hypoblast has been removed. The hypoblast expresses the chick orthologue of Cerberus (a BMP/Wnt/Nodal inhibitor), and the Nodal-specific short form Cer-S mimics the streak-inhibiting function of the hypoblast. Thus, the site of primitive streak formation is confined to the posterior side of the embryo by the anti-Nodal activity of the anteriorly moving hypoblast (Fig. 4a) [291].

FGFs are expressed before the onset of gastrulation [289] and functional FGF signalling is required for mesoderm formation in chick [47]. However, FGFs also play an
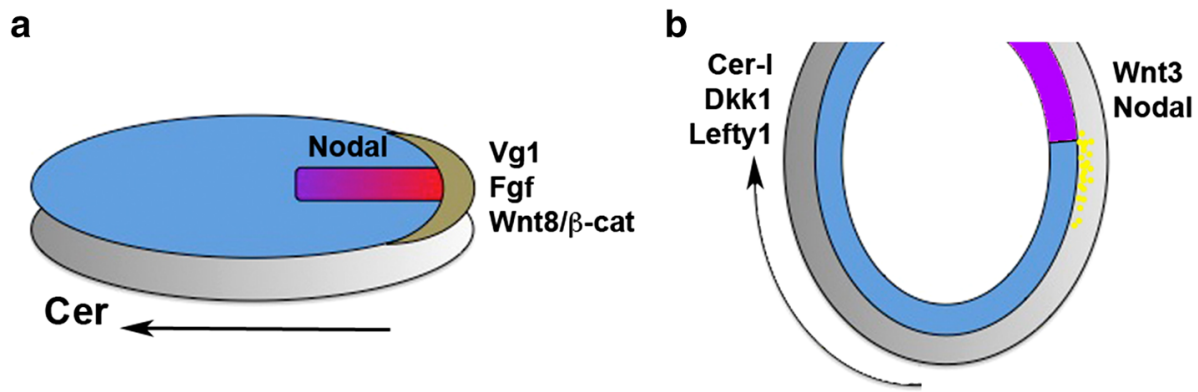

Fig. 4 Germ layer specification and related gene expression in early gastrula chick (a) and mouse (b) embryos. Anterior points to the left, dorsal is up. The germ layers are colour-coded as in Fig. 1. Extraembryonic tissues (hypoblast in chick, visceral endoderm in mouse) are shown in grey, Koller's sickle in brown. Note extension of the primitive streak from the posterior end of the embryo (red/purple) and simultaneous anterior displacement of the anterior hypoblast/AVE (dark grey). Endoderm (yellow dots in b) and mesoderm intercalate between the epiblast and the extraembryonic layers during gastrulation 
important role in neural induction in the chick embryo [292, 293]. The switch between mesoderm and neural induction by FGF is mediated by the zinc finger protein Churchill which is induced by FGF and activates Smad interacting protein 1 (SIP1) which subsequently blocks mesoderm induction [294].

Increased nuclear localisation of $\beta$-catenin marks the dorsal side of frog and fish embryos at blastula stages [89]. Nuclear localisation of $\beta$-catenin is also observed before the onset of gastrulation in chick: initially it is found radially in the marginal zone of the epiblast, but with the appearance of Koller's sickle it is also seen in endoblast cells that spread out beneath the epiblast from posterior to anterior [295]. Thus, despite their morphological differences, $\beta$-catenin activation appears to mark the site of organiser formation in both anamniotes and amniotes. Remarkably Cerberus (expressed in the hypoblast), has the ability to inhibit Wnt as well as Nodal signalling; thus, it is conceivable that the anterior displacement of the hypoblast by the endoblast positions the primitive streak via a dual inhibition mechanism involving both Wnt and Nodal signalling.

In anamniotes the mesoderm forms in a circumblastoporal ring that surrounds the entirety of the embryo whereas it only forms on the posterior side in amniotes. A recent study suggested that it is the posterior restriction of mesoderm-inducing FGF and Wnt signals that limit mesoderm induction to the streak in amniotes. Indeed, exogenous application of FGF protein to amniote embryos results in mesoderm induction throughout the entire marginal zone around the epiblast and a concomitant reduction of the streak [24], substantiating the previously suggested relationship between the anamniote blastopore lip and the amniote primitive streak [281].

\section{Germ layer formation in the mouse}

The pre-gastrula stage mouse embryo is cup-shaped and consists of an extraembryonic outer layer, the visceral endoderm, and an inner layer, the epiblast that gives rise to the embryo proper. Gastrulation begins on one side of the cup, marking the future posterior side of the embryo, and involves the formation of a primitive streak with the organiser (node) at its tip [296]. Prior to gastrulation, visceral endoderm that is located at the distal tip of the cup moves to the anterior side, similar to the anterior movement of the hypoblast in the chick. This anterior visceral endoderm (AVE) expresses the Nodal antagonists Cerberus-like and Lefty1 and the Wnt inhibitor Dickkopf1, confining Nodal and Wnt signalling to the posterior side of the cup (Fig. 4b) [297, 298]. Thus, despite different morphologies, chick and mouse embryos are rather similar with the chick hypoblast being the equivalent of the murine visceral endoderm [291].

Nodal is strictly required for mesendoderm formation in the mouse [65, 66]; however, the expression of Nodal in the early mouse embryo is surprisingly dynamic [299], suggesting that other factors restrict mesendoderm induction in the mouse. Unlike in other vertebrate models, BMP4 is also required for mesoderm formation in the mouse [300].

Similar to the other vertebrate models, early Wnt signalling appears to play an important role in breaking embryonic symmetry in the mouse [298]. Both genetic loss of the Wnt inhibitor Axin and transgenic overexpression of chick Wnt8c result in the formation of multiple primitive streaks-similar to the effect of ectopic Wnt expression in frog and fish [301]. Wnt3 is expressed in the right location and early enough to provide this axis-inducing signal, and its disruption results in a complete absence of mesoderm, primitive streak and node. Accordingly, Nodal is not expressed in Wnt 3 knockout mice [302]. This is in contrast to anamniote embryos where the dorsalising $\mathrm{Wnt} / \beta$-catenin signal can largely be uncoupled from the mesendoderminducing Nodal signal (see above).

Taken together, despite differing embryonic geometries, most of the key factors that mediate germ layer specification are conserved between anamniotes and amniotes.

\section{Targeted programming of stem cells}

The targeted differentiation of embryonic stem cells (ESCs) into virtually any tissue type holds great therapeutic promise for regenerative medicine. A thorough understanding as to how a tissue is generated in the developing organism can help us to recapitulate the underlying developmental programme in vitro. Since germ layer specification is the first step in the differentiation of all embryonic tissues, our knowledge of the GRNs that specify the endoderm, mesoderm and ectoderm is fundamental to devise sound stem cell differentiation protocols.

The major signalling pathways involved in mesendoderm specification in vertebrate embryos also result in the induction of comparable cell fates in ESCs: addition of either BMP4 or Wnt protein to ESC cultures results in the formation of primitive streak-like mesoderm [303-305] whereas Nodal induces mesoderm at lower and endoderm at higher doses [306]. Wnt signalling is not only sufficient, but also necessary for ESC mesoderm induction [307]. In contrast, BMP4 is not required suggesting that its ability to induce mesoderm is mediated indirectly via the induction of other mesoderm inducers (Nodal and Wnts) (reviewed in [308]). 
Using geometrically defined cultures of human stem cells, the Brivanlou lab recently showed that, if these cells are grown in the shape of a disc, they respond to treatment with BMP4 by forming concentric circles of ectoderm, mesoderm and extraembryonic trophectoderm, essentially recapitulating the spatial arrangement found in mammalian embryos. In these experiments they also found that the effect of BMP4 is mediated via the induction of Activin/ Nodal signalling that is induced in an increasing inside-out gradient [309]. Thus, by combining developmental signals with geometric constraints, the earliest steps of embryonic development can be fairly faithfully recapitulated in a dish.

\section{Concluding remarks}

Pioneering studies in amphibian embryos paved the way for current work aiming to assemble the GRN of germ layer specification in different species. Diffusible signals (such as the Nodals and FGFs) and a few maternal transcription factors are required for the initial specification of the germ layers. The combination of these induces germ layer-specific sets of transcription factors that regulate the subsequent acquisition and segregation of cell fates. Many of these factors cross-repress each other, which stabilises alternative cell fate decisions.

Although the formation of the germ layers is the earliest step in cell fate specification, the underlying GRN that mediates this decision is bafflingly complex, involving multiple secreted signalling factors and cascades of transcription factors many of which cross-regulate each other. The knowledge of this network is now being employed to drive stem cells along desired routes of specification.

\begin{abstract}
Acknowledgments We thank Anthony Graham for his helpful comments on the manuscript and apologise to the many researchers whose work we were not able to cite due to space constraints.
\end{abstract}

Open Access This article is distributed under the terms of the Creative Commons Attribution 4.0 International License (http:// creativecommons.org/licenses/by/4.0/), which permits unrestricted use, distribution, and reproduction in any medium, provided you give appropriate credit to the original author(s) and the source, provide a link to the Creative Commons license, and indicate if changes were made.

\section{References}

1. Vogt (1929) Gestaltungsanalyse am Amphibienkeim mit örtlicher Vitalfärbung. II. Gastrulation und Mesodermbildung bei Urodelen und Anuren. W Roux'Arch Entw mech Org 120:384-706

2. Toivonen S (1953) Bone-marrow of the guinea-pig as a mesodermal inductor in implantation experiments with embryos of triturus. J Embryol Exp Morphol 1953(1):97-104
3. Nieuwkoop PD (1967) The “organization centre”. II. Field phenomena, their origin and significance. Acta Biotheor 17(4):151-177

4. Nieuwkoop PD (1973) The organization center of the amphibian embryo: its origin, spatial organization, and morphogenetic action. Adv Morphog 10:1-39

5. Spemann Mangold (1924) Über Induktion von Embryonalanlagen durch Implantation artfremder Organisatoren. Arch Mikr Anat Entw Mech 100:599-638

6. Smith JC, Slack JM (1983) Dorsalization and neural induction: properties of the organizer in Xenopus laevis. J Embryol Exp Morphol 78:299-317

7. Gimlich RL, Gerhart JC (1984) Early cellular interactions promote embryonic axis formation in Xenopus laevis. Dev Biol 104(1):117-130

8. Dale L, Slack JM (1987) Regional specification within the mesoderm of early embryos of Xenopus laevis. Development (Cambridge, England) 100(2):279-295

9. Harland R, Gerhart J (1997) Formation and function of Spemann's organizer. Annu Rev Cell Dev Biol 13:611-667

10. Stern CD (2001) Initial patterning of the central nervous system: how many organizers? Nat Rev Neurosci 2(2):92-98

11. De Robertis EM, Kuroda H (2004) Dorsal-ventral patterning and neural induction in Xenopus embryos. Annu Rev Cell Dev Biol 20:285-308

12. Niehrs C (2004) Regionally specific induction by the SpemannMangold organizer. Nat Rev Genet 5(6):425-434

13. De Robertis EM (2009) Spemann's organizer and the self-regulation of embryonic fields. Mech Dev 126(11-12):925-941

14. Grant P, Wacaster JF (1972) The amphibian gray crescent region-a site of developmental information? Dev Biol 28(3):454-471

15. Vincent JP, Gerhart JC (1987) Subcortical rotation in Xenopus eggs: an early step in embryonic axis specification. Dev Biol 123(2):526-539

16. Holowacz T, Elinson RP (1993) Cortical cytoplasm, which induces dorsal axis formation in Xenopus, is inactivated by UV irradiation of the oocyte. Development (Cambridge, England) 119(1):277-285

17. Slack JM, Darlington BG, Heath JK, Godsave SF (1987) Mesoderm induction in early Xenopus embryos by heparinbinding growth factors. Nature 326(6109):197-200

18. Kimelman D, Abraham JA, Haaparanta T, Palisi TM, Kirschner MW (1988) The presence of fibroblast growth factor in the frog egg: its role as a natural mesoderm inducer. Science (New York, NY) 242(4881):1053-1056

19. LaBonne C, Burke B, Whitman M (1995) Role of MAP kinase in mesoderm induction and axial patterning during Xenopus development. Development (Cambridge, England) 121(5):1475-1486

20. Umbhauer M, Marshall CJ, Mason CS, Old RW, Smith JC (1995) Mesoderm induction in Xenopus caused by activation of MAP kinase. Nature 376(6535):58-62

21. Lustig KD, Kroll KL, Sun EE, Kirschner MW (1996) Expression cloning of a Xenopus T-related gene (Xombi) involved in mesodermal patterning and blastopore lip formation. Development (Cambridge, England) 122(12):4001-4012

22. Weinstein DC, Marden J, Carnevali F, Hemmati-Brivanlou A (1998) FGF-mediated mesoderm induction involves the Srcfamily kinase Laloo. Nature 394(6696):904-908

23. Cao Y, Zhao J, Sun Z, Zhao Z, Postlethwait J, Meng A (2004) fgf17b, a novel member of Fgf family, helps patterning zebrafish embryos. Dev Biol 271(1):130-143

24. Alev C, Wu Y, Nakaya Y, Sheng G (2013) Decoupling of amniote gastrulation and streak formation reveals a morphogenetic unity in vertebrate mesoderm induction. Development (Cambridge, England) 140(13):2691-2696 
25. Burdsal CA, Flannery ML, Pedersen RA (1998) FGF-2 alters the fate of mouse epiblast from ectoderm to mesoderm in vitro. Dev Biol 198(2):231-244

26. Mitrani E, Gruenbaum Y, Shohat H, Ziv T (1990) Fibroblast growth factor during mesoderm induction in the early chick embryo. Development (Cambridge, England) 109(2):387-393

27. Amaya E, Musci TJ, Kirschner MW (1991) Expression of a dominant negative mutant of the FGF receptor disrupts mesoderm formation in Xenopus embryos. Cell 66(2):257-270

28. Fletcher RB, Harland RM (2008) The role of FGF signaling in the establishment and maintenance of mesodermal gene expression in Xenopus. Dev Dyn 237(5):1243-1254

29. Lea R, Papalopulu N, Amaya E, Dorey K (2009) Temporal and spatial expression of FGF ligands and receptors during Xenopus development. Dev Dyn 238(6):1467-1479

30. Furthauer M, Van Celst J, Thisse C, Thisse B (2004) Fgf signalling controls the dorsoventral patterning of the zebrafish embryo. Development (Cambridge, England) 131(12):2853-2864

31. Furthauer M, Thisse C, Thisse B (1997) A role for FGF-8 in the dorsoventral patterning of the zebrafish gastrula. Development (Cambridge, England) 124(21):4253-4264

32. Lee SY, Lim SK, Cha SW, Yoon J, Lee SH, Lee HS et al (2011) Inhibition of FGF signaling converts dorsal mesoderm to ventral mesoderm in early Xenopus embryos. Differentiation 82(2):99-107

33. Kimelman D, Kirschner M (1987) Synergistic induction of mesoderm by FGF and TGF-beta and the identification of an mRNA coding for FGF in the early Xenopus embryo. Cell 51(5):869-877

34. Cornell RA, Kimelman D (1994) Activin-mediated mesoderm induction requires FGF. Development (Cambridge, England) 120(2):453-462

35. LaBonne C, Whitman M (1994) Mesoderm induction by activin requires FGF-mediated intracellular signals. Development (Cambridge, England) 120(2):463-472

36. Mitchell TS, Sheets MD (2001) The FGFR pathway is required for the trunk-inducing functions of Spemann's organizer. Dev Biol 237(2):295-305

37. Mathieu J, Griffin K, Herbomel P, Dickmeis T, Strahle U, Kimelman D et al (2004) Nodal and Fgf pathways interact through a positive regulatory loop and synergize to maintain mesodermal cell populations. Development (Cambridge, England) 131(3):629-641

38. Rodaway A, Takeda H, Koshida S, Broadbent J, Price B, Smith JC et al (1999) Induction of the mesendoderm in the zebrafish germ ring by yolk cell-derived TGF-beta family signals and discrimination of mesoderm and endoderm by FGF. Development (Cambridge, England) 126(14):3067-3078

39. Asashima M, Nakano H, Uchiyama H, Sugino H, Nakamura T, Eto $Y$ et al (1991) Presence of activin (erythroid differentiation factor) in unfertilized eggs and blastulae of Xenopus laevis. Proc Natl Acad Sci USA 88(15):6511-6514

40. Smith JC, Price BM, Van Nimmen K, Huylebroeck D (1990) Identification of a potent Xenopus mesoderm-inducing factor as a homologue of activin A. Nature 345(6277):729-731

41. Thomsen G, Woolf T, Whitman M, Sokol S, Vaughan J, Vale W et al (1990) Activins are expressed early in Xenopus embryogenesis and can induce axial mesoderm and anterior structures. Cell 63(3):485-493

42. Ninomiya H, Takahashi S, Tanegashima K, Yokota C, Asashima M (1999) Endoderm differentiation and inductive effect of activin-treated ectoderm in Xenopus. Dev Growth Differ 41(4):391-400

43. Green JB, Smith JC (1990) Graded changes in dose of a Xenopus activin A homologue elicit stepwise transitions in embryonic cell fate. Nature 347(6291):391-394
44. Weber H, Holewa B, Jones EA, Ryffel GU (1996) Mesoderm and endoderm differentiation in animal cap explants: identification of the HNF4-binding site as an activin A responsive element in the Xenopus HNF1alpha promoter. Development (Cambridge, England) 122(6):1975-1984

45. Hudson C, Clements D, Friday RV, Stott D, Woodland HR (1997) Xsox 17alpha and -beta mediate endoderm formation in Xenopus. Cell 91(3):397-405

46. Wittbrodt J, Rosa FM (1994) Disruption of mesoderm and axis formation in fish by ectopic expression of activin variants: the role of maternal activin. Genes Dev 8(12):1448-1462

47. Mitrani E, Ziv T, Thomsen G, Shimoni Y, Melton DA, Bril A (1990) Activin can induce the formation of axial structures and is expressed in the hypoblast of the chick. Cell 63(3):495-501

48. Schulte-Merker S, Smith JC, Dale L (1994) Effects of truncated activin and FGF receptors and of follistatin on the inducing activities of $\mathrm{BVg} 1$ and activin: does activin play a role in mesoderm induction? EMBO J 13(15):3533-3541

49. Marchant L, Linker C, Mayor R (1998) Inhibition of mesoderm formation by follistatin. Dev Genes Evol 208(3):157-160

50. Matzuk MM, Kumar TR, Bradley A (1995) Different phenotypes for mice deficient in either activins or activin receptor type II. Nature 374(6520):356-360

51. Piepenburg O, Grimmer D, Williams PH, Smith JC (2004) Activin redux: specification of mesodermal pattern in Xenopus by graded concentrations of endogenous activin B. Development (Cambridge, England) 131(20):4977-4986

52. Bates TJ, Vonica A, Heasman J, Brivanlou AH, Bell E (2013) Coco regulates dorsoventral specification of germ layers via inhibition of TGFbeta signalling. Development (Cambridge, England) 140(20):4177-4181

53. Hemmati-Brivanlou A, Melton DA (1992) A truncated activin receptor inhibits mesoderm induction and formation of axial structures in Xenopus embryos. Nature 359(6396):609-614

54. Weeks DL, Melton DA (1987) A maternal mRNA localized to the vegetal hemisphere in Xenopus eggs codes for a growth factor related to TGF-beta. Cell 51(5):861-867

55. Dale L, Matthews G, Colman A (1993) Secretion and mesoderm-inducing activity of the TGF-beta-related domain of Xenopus Vg1. EMBO J 12(12):4471-4480

56. Thomsen GH, Melton DA (1993) Processed Vg1 protein is an axial mesoderm inducer in Xenopus. Cell 74(3):433-441

57. Birsoy B, Kofron M, Schaible K, Wylie C, Heasman J (2006) $\mathrm{Vg} 1$ is an essential signaling molecule in Xenopus development. Development (Cambridge, England) 133(1):15-20

58. Joseph EM, Melton DA (1998) Mutant Vg1 ligands disrupt endoderm and mesoderm formation in Xenopus embryos. Development (Cambridge, England) 125(14):2677-2685

59. Dohrmann CE, Kessler DS, Melton DA (1996) Induction of axial mesoderm by zDVR-1, the zebrafish orthologue of Xenopus Vg1. Dev Biol 175(1):108-117

60. Seleiro EA, Connolly DJ, Cooke J (1996) Early developmental expression and experimental axis determination by the chicken Vg1 gene. Curr Biol 6(11):1476-1486

61. Shah SB, Skromne I, Hume CR, Kessler DS, Lee KJ, Stern CD et al (1997) Misexpression of chick Vg1 in the marginal zone induces primitive streak formation. Development (Cambridge, England) 124(24):5127-5138

62. Peterson AG, Wang X, Yost HJ (2013) Dvr1 transfers left-right asymmetric signals from Kupffer's vesicle to lateral plate mesoderm in zebrafish. Dev Biol 382(1):198-208

63. Andersson O, Bertolino P, Ibanez CF (2007) Distinct and cooperative roles of mammalian $\mathrm{Vg} 1$ homologs GDF1 and GDF3 during early embryonic development. Dev Biol 311(2):500-511 
64. Sun BI, Bush SM, Collins-Racie LA, LaVallie ER, DiBlasioSmith EA, Wolfman NM et al (1999) derriere: a TGF-beta family member required for posterior development in Xenopus. Development (Cambridge, England) 126(7):1467-1482

65. Zhou X, Sasaki H, Lowe L, Hogan BL, Kuehn MR (1993) Nodal is a novel TGF-beta-like gene expressed in the mouse node during gastrulation. Nature 361(6412):543-547

66. Conlon FL, Lyons KM, Takaesu N, Barth KS, Kispert A, Herrmann B et al (1994) A primary requirement for nodal in the formation and maintenance of the primitive streak in the mouse. Development (Cambridge, England) 120(7):1919-1928

67. Feldman B, Gates MA, Egan ES, Dougan ST, Rennebeck G, Sirotkin HI et al (1998) Zebrafish organizer development and germ-layer formation require nodal-related signals. Nature 395(6698):181-185

68. Shen MM (2007) Nodal signaling: developmental roles and regulation. Development (Cambridge, England) 134(6):1023-1034

69. Schier AF (2009) Nodal morphogens. Cold Spring Harb Perspect Biol 1(5):a003459

70. Nomura M, Li E (1998) Smad2 role in mesoderm formation, left-right patterning and craniofacial development. Nature 393(6687):786-790

71. Sirard C, de la Pompa JL, Elia A, Itie A, Mirtsos C, Cheung A et al (1998) The tumor suppressor gene Smad4/Dpc4 is required for gastrulation and later for anterior development of the mouse embryo. Genes Dev 12(1):107-119

72. Yang J, Tan C, Darken RS, Wilson PA, Klein PS (2002) Betacatenin/Tcf-regulated transcription prior to the midblastula transition. Development (Cambridge, England) 129(24):5743-5752

73. Gritsman K, Zhang J, Cheng S, Heckscher E, Talbot WS, Schier AF (1999) The EGF-CFC protein one-eyed pinhead is essential for nodal signaling. Cell 97(1):121-132

74. Dunn NR, Vincent SD, Oxburgh L, Robertson EJ, Bikoff EK (2004) Combinatorial activities of Smad2 and Smad3 regulate mesoderm formation and patterning in the mouse embryo. Development (Cambridge, England) 131(8):1717-1728

75. Jones CM, Kuehn MR, Hogan BL, Smith JC, Wright CV (1995) Nodal-related signals induce axial mesoderm and dorsalize mesoderm during gastrulation. Development (Cambridge, England) 121(11):3651-3662

76. Smith WC, McKendry R, Ribisi S Jr, Harland RM (1995) A nodal-related gene defines a physical and functional domain within the Spemann organizer. Cell 82(1):37-46

77. Joseph EM, Melton DA (1997) Xnr4: a Xenopus nodal-related gene expressed in the Spemann organizer. Dev Biol 184(2):367-372

78. Takahashi S, Yokota C, Takano K, Tanegashima K, Onuma Y, Goto J et al (2000) Two novel nodal-related genes initiate early inductive events in Xenopus Nieuwkoop center. Development (Cambridge, England) 127(24):5319-5329

79. Luxardi G, Marchal L, Thome V, Kodjabachian L (2010) Distinct Xenopus Nodal ligands sequentially induce mesendoderm and control gastrulation movements in parallel to the Wnt/PCP pathway. Development (Cambridge, England) 137(3):417-426

80. Koster M, Plessow S, Clement JH, Lorenz A, Tiedemann H, Knochel W (1991) Bone morphogenetic protein 4 (BMP-4), a member of the TGF-beta family, in early embryos of Xenopus laevis: analysis of mesoderm inducing activity. Mech Dev 33(3):191-199

81. McMahon AP, Moon RT (1989) Ectopic expression of the proto-oncogene int-1 in Xenopus embryos leads to duplication of the embryonic axis. Cell 58(6):1075-1084

82. Smith WC, Harland RM (1991) Injected Xwnt-8 RNA acts early in Xenopus embryos to promote formation of a vegetal dorsalizing center. Cell 67(4):753-765
83. Moon RT, Campbell RM, Christian JL, McGrew LL, Shih J, Fraser S (1993) Xwnt-5A: a maternal Wnt that affects morphogenetic movements after overexpression in embryos of Xenopus laevis. Development (Cambridge, England) 119(1):97-111

84. Dominguez I, Itoh K, Sokol SY (1995) Role of glycogen synthase kinase 3 beta as a negative regulator of dorsoventral axis formation in Xenopus embryos. Proc Natl Acad Sci USA 92(18):8498-8502

85. Guger KA, Gumbiner BM (1995) beta-Catenin has Wnt-like activity and mimics the Nieuwkoop signaling center in Xenopus dorsal-ventral patterning. Dev Biol 172(1):115-125

86. He X, Saint-Jeannet JP, Woodgett JR, Varmus HE, Dawid IB (1995) Glycogen synthase kinase-3 and dorsoventral patterning in Xenopus embryos. Nature 374(6523):617-622

87. Lagna G, Carnevali F, Marchioni M, Hemmati-Brivanlou A (1999) Negative regulation of axis formation and Wnt signaling in Xenopus embryos by the F-box/WD40 protein beta TrCP. Mech Dev 80(1):101-106

88. Elinson RP, Rowning B (1988) A transient array of parallel microtubules in frog eggs: potential tracks for a cytoplasmic rotation that specifies the dorso-ventral axis. Dev Biol 128(1):185-197

89. Schneider S, Steinbeisser H, Warga RM, Hausen P (1996) Betacatenin translocation into nuclei demarcates the dorsalizing centers in frog and fish embryos. Mech Dev 57(2):191-198

90. Rowning BA, Wells J, Wu M, Gerhart JC, Moon RT, Larabell CA (1997) Microtubule-mediated transport of organelles and localization of beta-catenin to the future dorsal side of Xenopus eggs. Proc Natl Acad Sci USA 94(4):1224-1229

91. Miller JR, Rowning BA, Larabell CA, Yang-Snyder JA, Bates RL, Moon RT (1999) Establishment of the dorsal-ventral axis in Xenopus embryos coincides with the dorsal enrichment of dishevelled that is dependent on cortical rotation. J Cell Biol 146(2):427-437

92. Weaver C, Farr GH 3rd, Pan W, Rowning BA, Wang J, Mao J et al (2003) GBP binds kinesin light chain and translocates during cortical rotation in Xenopus eggs. Development (Cambridge, England) 130(22):5425-5436

93. Dominguez I, Green JB (2000) Dorsal downregulation of GSK3beta by a non-Wnt-like mechanism is an early molecular consequence of cortical rotation in early Xenopus embryos. Development (Cambridge, England) 127(4):861-868

94. Cui Y, Brown JD, Moon RT, Christian JL (1995) Xwnt-8b: a maternally expressed Xenopus Wnt gene with a potential role in establishing the dorsoventral axis. Development (Cambridge, England) 121(7):2177-2186

95. Ku M, Melton DA (1993) Xwnt-11: a maternally expressed Xenopus wnt gene. Development (Cambridge, England) 119(4):1161-1173

96. Torres MA, Yang-Snyder JA, Purcell SM, DeMarais AA, McGrew LL, Moon RT (1996) Activities of the Wnt-1 class of secreted signaling factors are antagonized by the Wnt-5A class and by a dominant negative cadherin in early Xenopus development. J Cell Biol 133(5):1123-1137

97. Yamaguchi TP, Bradley A, McMahon AP, Jones S (1999) A Wnt5a pathway underlies outgrowth of multiple structures in the vertebrate embryo. Development (Cambridge, England) 126(6):1211-1223

98. Heisenberg CP, Tada M, Rauch GJ, Saude L, Concha ML, Geisler R et al (2000) Silberblick/Wnt11 mediates convergent extension movements during zebrafish gastrulation. Nature 405(6782):76-81

99. Kilian B, Mansukoski H, Barbosa FC, Ulrich F, Tada M, Heisenberg CP (2003) The role of Ppt/Wnt5 in regulating cell shape and movement during zebrafish gastrulation. Mech Dev 120(4):467-476 
100. Wang S, Krinks M, Lin K, Luyten FP, Moos M Jr (1997) Frzb, a secreted protein expressed in the Spemann organizer, binds and inhibits Wnt-8. Cell 88(6):757-766

101. Tao Q, Yokota C, Puck H, Kofron M, Birsoy B, Yan D et al (2005) Maternal wnt11 activates the canonical wnt signaling pathway required for axis formation in Xenopus embryos. Cell 120(6):857-871

102. Schroeder KE, Condic ML, Eisenberg LM, Yost HJ (1999) Spatially regulated translation in embryos: asymmetric expression of maternal Wnt-11 along the dorsal-ventral axis in Xenopus. Dev Biol 214(2):288-297

103. Sumanas S, Strege P, Heasman J, Ekker SC (2000) The putative wnt receptor Xenopus frizzled-7 functions upstream of betacatenin in vertebrate dorsoventral mesoderm patterning. Development (Cambridge, England) 127(9):1981-1990

104. Kinoshita N, Minshull J, Kirschner MW (1995) The identification of two novel ligands of the FGF receptor by a yeast screening method and their activity in Xenopus development. Cell 83(4):621-630

105. Cha SW, Tadjuidje E, Tao Q, Wylie C, Heasman J (2008) Wnt5a and Wnt11 interact in a maternal Dkk1-regulated fashion to activate both canonical and non-canonical signaling in Xenopus axis formation. Development (Cambridge, England) 135(22):3719-3729

106. Cha SW, Tadjuidje E, White J, Wells J, Mayhew C, Wylie C et al (2009) Wnt11/5a complex formation caused by tyrosine sulfation increases canonical signaling activity. Curr Biol 19(18): 1573-1580

107. Kofron M, Birsoy B, Houston D, Tao Q, Wylie C, Heasman J (2007) Wnt11/beta-catenin signaling in both oocytes and early embryos acts through LRP6-mediated regulation of axin. Development (Cambridge, England) 134(3):503-513

108. Baker JC, Beddington RS, Harland RM (1999) Wnt signaling in Xenopus embryos inhibits bmp4 expression and activates neural development. Genes Dev 13(23):3149-3159

109. Wessely O, Agius E, Oelgeschlager M, Pera EM, De Robertis EM (2001) Neural induction in the absence of mesoderm: betacatenin-dependent expression of secreted BMP antagonists at the blastula stage in Xenopus. Dev Biol 234(1):161-173

110. Kuroda H, Wessely O, De Robertis EM (2004) Neural induction in Xenopus: requirement for ectodermal and endomesodermal signals via Chordin, Noggin, beta-Catenin, and Cerberus. PLoS Biol 2(5):E92

111. Agius E, Oelgeschlager M, Wessely O, Kemp C, De Robertis EM (2000) Endodermal Nodal-related signals and mesoderm induction in Xenopus. Development (Cambridge, England) 127(6):1173-1183

112. Rex M, Hilton E, Old R (2002) Multiple interactions between maternally-activated signalling pathways control Xenopus nodal-related genes. Int J Dev Biol 46(2):217-226

113. Hansen CS, Marion CD, Steele K, George S, Smith WC (1997) Direct neural induction and selective inhibition of mesoderm and epidermis inducers by Xnr3. Development (Cambridge, England) 124(2):483-492

114. Hyde CE, Old RW (2000) Regulation of the early expression of the Xenopus nodal-related 1 gene, Xnr1. Development (Cambridge, England) 127(6):1221-1229

115. Schohl A, Fagotto F (2003) A role for maternal beta-catenin in early mesoderm induction in Xenopus. EMBO $\mathbf{J}$ 22(13):3303-3313

116. Gritsman K, Talbot WS, Schier AF (2000) Nodal signaling patterns the organizer. Development (Cambridge, England) 127(5):921-932

117. Dougan ST, Warga RM, Kane DA, Schier AF, Talbot WS (2003) The role of the zebrafish nodal-related genes squint and cyclops in patterning of mesendoderm. Development (Cambridge, England) 130(9):1837-1851

118. Keegan BR, Meyer D, Yelon D (2004) Organization of cardiac chamber progenitors in the zebrafish blastula. Development (Cambridge, England) 131(13):3081-3091

119. Osada SI, Wright CV (1999) Xenopus nodal-related signaling is essential for mesendodermal patterning during early embryogenesis. Development (Cambridge, England) 126(14):3229-3240

120. Kessler DS, Melton DA (1995) Induction of dorsal mesoderm by soluble, mature Vg1 protein. Development (Cambridge, England) 121(7):2155-2164

121. Thisse B, Wright CV, Thisse C (2000) Activin- and Nodalrelated factors control antero-posterior patterning of the zebrafish embryo. Nature 403(6768):425-428

122. Rebagliati MR, Dawid IB (1993) Expression of activin transcripts in follicle cells and oocytes of Xenopus laevis. Dev Biol 159(2):574-580

123. Fauré S, Lee MA, Keller T, ten Dijke P, Whitman M (2000) Endogenous patterns of TGFbeta superfamily signaling during early Xenopus development. Development (Cambridge, England) 127(13):2917-2931

124. Schohl A, Fagotto F (2002) Beta-catenin, MAPK and Smad signaling during early Xenopus development. Development (Cambridge, England) 129(1):37-52

125. Harvey SA, Smith JC (2009) Visualisation and quantification of morphogen gradient formation in the zebrafish. PLoS Biol 7(5):e1000101

126. Dubrulle J, Jordan BM, Akhmetova L, Farrell JA, Kim SH, Solnica-Krezel L et al (2015) Response to Nodal morphogen gradient is determined by the kinetics of target gene induction. eLife 4

127. Curran KL, Grainger RM (2000) Expression of activated MAP kinase in Xenopus laevis embryos: evaluating the roles of FGF and other signaling pathways in early induction and patterning. Dev Biol 228(1):41-56

128. Christen B, Slack JM (1999) Spatial response to fibroblast growth factor signalling in Xenopus embryos. Development (Cambridge, England) 126(1):119-125

129. LaBonne C, Whitman M (1997) Localization of MAP kinase activity in early Xenopus embryos: implications for endogenous FGF signaling. Dev Biol 183(1):9-20

130. Cordenonsi M, Montagner M, Adorno M, Zacchigna L, Martello G, Mamidi A et al (2007) Integration of TGF-beta and Ras/ MAPK signaling through p53 phosphorylation. Science (New York, NY) 315(5813):840-843

131. Bell E, Munoz-Sanjuan I, Altmann CR, Vonica A, Brivanlou AH (2003) Cell fate specification and competence by Coco, a maternal BMP, TGFbeta and Wnt inhibitor. Development (Cambridge, England) 130(7):1381-1389

132. Xu S, Cheng F, Liang J, Wu W, Zhang J (2012) Maternal xNorrin, a canonical Wnt signaling agonist and TGF-beta antagonist, controls early neuroectoderm specification in Xenopus. PLoS Biol 10(3):e1001286

133. Xu Q, Wang Y, Dabdoub A, Smallwood PM, Williams J, Woods $C$ et al (2004) Vascular development in the retina and inner ear: control by Norrin and Frizzled-4, a high-affinity ligand-receptor pair. Cell 116(6):883-895

134. Dupont S, Zacchigna L, Cordenonsi M, Soligo S, Adorno M, Rugge $M$ et al (2005) Germ-layer specification and control of cell growth by Ectodermin, a Smad4 ubiquitin ligase. Cell 121(1):87-99

135. Sivak JM, Petersen LF, Amaya E (2005) FGF signal interpretation is directed by Sprouty and Spred proteins during mesoderm formation. Dev Cell 8(5):689-701 
136. Glinka A, Wu W, Delius H, Monaghan AP, Blumenstock C, Niehrs C (1998) Dickkopf-1 is a member of a new family of secreted proteins and functions in head induction. Nature 391(6665):357-362

137. Stambolic V, Ruel L, Woodgett JR (1996) Lithium inhibits glycogen synthase kinase-3 activity and mimics wingless signalling in intact cells. Curr Biol 6(12):1664-1668

138. Behrens J, Jerchow BA, Wurtele M, Grimm J, Asbrand C, Wirtz $\mathrm{R}$ et al (1998) Functional interaction of an axin homolog, conductin, with beta-catenin, APC, and GSK3beta. Science (New York, NY) 280(5363):596-599

139. Itoh K, Krupnik VE, Sokol SY (1998) Axis determination in Xenopus involves biochemical interactions of axin, glycogen synthase kinase 3 and beta-catenin. Curr Biol 8(10):591-594

140. Marikawa Y, Elinson RP (1998) beta-TrCP is a negative regulator of Wnt/beta-catenin signaling pathway and dorsal axis formation in Xenopus embryos. Mech Dev 77(1):75-80

141. Yamamoto H, Kishida S, Uochi T, Ikeda S, Koyama S, Asashima $M$ et al (1998) Axil, a member of the Axin family, interacts with both glycogen synthase kinase 3 beta and betacatenin and inhibits axis formation of Xenopus embryos. Mol Cell Biol 18(5):2867-2875

142. Yost C, Farr GH 3rd, Pierce SB, Ferkey DM, Chen MM, Kimelman D (1998) GBP, an inhibitor of GSK-3, is implicated in Xenopus development and oncogenesis. Cell 93(6): 1031-1041

143. Hedgepeth CM, Deardorff MA, Rankin K, Klein PS (1999) Regulation of glycogen synthase kinase 3beta and downstream Wnt signaling by axin. Mol Cell Biol 19(10):7147-7157

144. Liu C, Kato Y, Zhang Z, Do VM, Yankner BA, He X (1999) beta-Trcp couples beta-catenin phosphorylation-degradation and regulates Xenopus axis formation. Proc Natl Acad Sci USA 96(11):6273-6278

145. Stennard F, Carnac G, Gurdon JB (1996) The Xenopus T-box gene, Antipodean, encodes a vegetally localised maternal mRNA and can trigger mesoderm formation. Development (Cambridge, England) 122(12):4179-4188

146. Zhang J, King ML (1996) Xenopus VegT RNA is localized to the vegetal cortex during oogenesis and encodes a novel T-box transcription factor involved in mesodermal patterning. Development (Cambridge, England) 122(12):4119-4129

147. Horb ME, Thomsen GH (1997) A vegetally localized T-box transcription factor in Xenopus eggs specifies mesoderm and endoderm and is essential for embryonic mesoderm formation. Development (Cambridge, England) 124(9):1689-1698

148. Kurth T, Hausen P (2000) Bottle cell formation in relation to mesodermal patterning in the Xenopus embryo. Mech Dev 97(1-2):117-131

149. Zhang J, Houston DW, King ML, Payne C, Wylie C, Heasman J (1998) The role of maternal VegT in establishing the primary germ layers in Xenopus embryos. Cell 94(4):515-524

150. Kavka AI, Green JB (2000) Evidence for dual mechanisms of mesoderm establishment in Xenopus embryos. Dev Dyn 219(1):77-83

151. Skirkanich J, Luxardi G, Yang J, Kodjabachian L, Klein PS (2011) An essential role for transcription before the MBT in Xenopus laevis. Dev Biol 357(2):478-491

152. Fukuda M, Takahashi S, Haramoto Y, Onuma Y, Kim YJ, Yeo CY et al (2010) Zygotic VegT is required for Xenopus paraxial mesoderm formation and is regulated by Nodal signaling and Eomesodermin. Int J Dev Biol 54(1):81-92

153. Holewa B, Strandmann EP, Zapp D, Lorenz P, Ryffel GU (1996) Transcriptional hierarchy in Xenopus embryogenesis: HNF4 a maternal factor involved in the developmental activation of the gene encoding the tissue specific transcription factor HNF1 alpha (LFB1). Mech Dev 54(1):45-57
154. Vignali R, Poggi L, Madeddu F, Barsacchi G (2000) HNF1(beta) is required for mesoderm induction in the Xenopus embryo. Development (Cambridge, England) 127(7):1455-1465

155. Ishibashi $\mathrm{H}$, Matsumura $\mathrm{N}$, Hanafusa $\mathrm{H}$, Matsumoto $\mathrm{K}$, De Robertis EM, Kuroda H (2008) Expression of Siamois and Twin in the blastula Chordin/Noggin signaling center is required for brain formation in Xenopus laevis embryos. Mech Dev 125(1-2):58-66

156. Lemaire P, Garrett N, Gurdon JB (1995) Expression cloning of Siamois, a Xenopus homeobox gene expressed in dorsal-vegetal cells of blastulae and able to induce a complete secondary axis. Cell 81(1):85-94

157. Brannon M, Kimelman D (1996) Activation of Siamois by the Wnt pathway. Dev Biol 180(1):344-347

158. Carnac G, Kodjabachian L, Gurdon JB, Lemaire P (1996) The homeobox gene Siamois is a target of the Wnt dorsalisation pathway and triggers organiser activity in the absence of mesoderm. Development (Cambridge, England) 122(10):3055-3065

159. Fagotto F, Guger K, Gumbiner BM (1997) Induction of the primary dorsalizing center in Xenopus by the Wnt/GSK/betacatenin signaling pathway, but not by $\mathrm{Vg} 1$, Activin or Noggin. Development (Cambridge, England) 124(2):453-460

160. Fan MJ, Gruning W, Walz G, Sokol SY (1998) Wnt signaling and transcriptional control of Siamois in Xenopus embryos. Proc Natl Acad Sci USA 95(10):5626-5631

161. Laurent MN, Blitz IL, Hashimoto C, Rothbacher U, Cho KW (1997) The Xenopus homeobox gene twin mediates Wnt induction of goosecoid in establishment of Spemann's organizer. Development (Cambridge, England) 124(23):4905-4916

162. Bae S, Reid CD, Kessler DS (2011) Siamois and Twin are redundant and essential in formation of the Spemann organizer. Dev Biol 352(2):367-381

163. Bouwmeester T, Kim S, Sasai Y, Lu B, De Robertis EM (1996) Cerberus is a head-inducing secreted factor expressed in the anterior endoderm of Spemann's organizer. Nature 382(6592):595-601

164. Piccolo S, Agius E, Leyns L, Bhattacharyya S, Grunz H, Bouwmeester T et al (1999) The head inducer Cerberus is a multifunctional antagonist of Nodal, BMP and Wnt signals. Nature 397(6721):707-710

165. Sudou N, Yamamoto S, Ogino H, Taira M (2012) Dynamic in vivo binding of transcription factors to cis-regulatory modules of cer and gsc in the stepwise formation of the Spemann-Mangold organizer. Development (Cambridge, England) 139(9):1651-1661

166. Fekany K, Yamanaka Y, Leung T, Sirotkin HI, Topczewski J, Gates MA et al (1999) The zebrafish bozozok locus encodes Dharma, a homeodomain protein essential for induction of gastrula organizer and dorsoanterior embryonic structures. Development (Cambridge, England) 126(7):1427-1438

167. Ryu SL, Fujii R, Yamanaka Y, Shimizu T, Yabe T, Hirata T et al (2001) Regulation of dharma/bozozok by the Wnt pathway. Dev Biol 231(2):397-409

168. Leung T, Bischof J, Soll I, Niessing D, Zhang D, Ma J et al (2003) bozozok directly represses bmp2b transcription and mediates the earliest dorsoventral asymmetry of bmp2b expression in zebrafish. Development (Cambridge, England) 130(16):3639-3649

169. Ro H, Dawid IB (2009) Organizer restriction through modulation of Bozozok stability by the E3 ubiquitin ligase Lnx-like. Nat Cell Biol 11(9):1121-1127

170. Clark FH (1934) Linkage studies of Brachyury (Short Tail) in the house mouse. Proc Natl Acad Sci USA 20(5):276-279

171. Chesley P, Dunn LC (1936) The inheritance of taillessness (Anury) in the house mouse. Genetics 21(5):525-536 
172. Gluecksohn-Schoenheimer S (1944) The development of normal and homozygous brachy (T/T) mouse embryos in the extraembryonic coelom of the chick. Proc Natl Acad Sci USA 30(6): 134-140

173. Fujimoto H, Yanagisawa KO (1983) Defects in the archenteron of mouse embryos homozygous for the T-mutation. Differentiation 25(1):44-47

174. Herrmann BG, Labeit S, Poustka A, King TR, Lehrach H (1990) Cloning of the $\mathrm{T}$ gene required in mesoderm formation in the mouse. Nature 343(6259):617-622

175. Wilkinson DG, Bhatt S, Herrmann BG (1990) Expression pattern of the mouse $\mathrm{T}$ gene and its role in mesoderm formation. Nature 343(6259):657-659

176. Smith JC, Price BM, Green JB, Weigel D, Herrmann BG (1991) Expression of a Xenopus homolog of Brachyury (T) is an immediate-early response to mesoderm induction. Cell 67(1):79-87

177. Sokol SY, Melton DA (1992) Interaction of Wnt and activin in dorsal mesoderm induction in Xenopus. Dev Biol 154(2):348-355

178. Kispert A, Herrmann BG (1993) The Brachyury gene encodes a novel DNA binding protein. EMBO J 12(8):3211-3220

179. Kispert A, Koschorz B, Herrmann BG (1995) The T protein encoded by Brachyury is a tissue-specific transcription factor. EMBO J 14(19):4763-4772

180. Cunliffe V, Smith JC (1992) Ectopic mesoderm formation in Xenopus embryos caused by widespread expression of a Brachyury homologue. Nature 358(6385):427-430

181. Conlon FL, Sedgwick SG, Weston KM, Smith JC (1996) Inhibition of Xbra transcription activation causes defects in mesodermal patterning and reveals autoregulation of Xbra in dorsal mesoderm. Development (Cambridge, England) 122(8):2427-2435

182. Isaacs HV, Pownall ME, Slack JM (1994) eFGF regulates Xbra expression during Хenopus gastrulation. EMBO J 13(19):4469-4481

183. Latinkic BV, Umbhauer M, Neal KA, Lerchner W, Smith JC, Cunliffe V (1997) The Xenopus Brachyury promoter is activated by FGF and low concentrations of activin and suppressed by high concentrations of activin and by paired-type homeodomain proteins. Genes Dev 11(23):3265-3276

184. Schulte-Merker S, Smith JC (1995) Mesoderm formation in response to Brachyury requires FGF signalling. Curr Biol 5(1):62-67

185. Green JB, Smith JC, Gerhart JC (1994) Slow emergence of a multithreshold response to activin requires cell-contact-dependent sharpening but not prepattern. Development (Cambridge, England) 120(8):2271-2278

186. Northrop JL, Kimelman D (1994) Dorsal-ventral differences in Xcad-3 expression in response to FGF-mediated induction in Xenopus. Dev Biol 161(2):490-503

187. Gurdon JB, Mitchell A, Ryan K (1996) An experimental system for analyzing response to a morphogen gradient. Proc Natl Acad Sci USA 93(18):9334-9338

188. Saka Y, Tada M, Smith JC (2000) A screen for targets of the Xenopus T-box gene Xbra. Mech Dev 93(1-2):27-39

189. Tada M, Casey ES, Fairclough L, Smith JC (1998) Bix1, a direct target of Xenopus T-box genes, causes formation of ventral mesoderm and endoderm. Development (Cambridge, England) 125(20):3997-4006

190. Tada M, Smith JC (2000) Xwnt11 is a target of Xenopus Brachyury: regulation of gastrulation movements via Dishevelled, but not through the canonical Wnt pathway. Development (Cambridge, England) 127(10):2227-2238

191. Panitz F, Krain B, Hollemann T, Nordheim A, Pieler T (1998) The Spemann organizer-expressed zinc finger gene Xegr-1 responds to the MAP kinase/Ets-SRF signal transduction pathway. EMBO J 17(15):4414-4425

192. Ryan K, Garrett N, Mitchell A, Gurdon JB (1996) Eomesodermin, a key early gene in Xenopus mesoderm differentiation. Cell 87(6):989-1000

193. Ryan K, Garrett N, Bourillot P, Stennard F, Gurdon JB (2000) The Xenopus eomesodermin promoter and its concentrationdependent response to activin. Mech Dev 94(1-2):133-146

194. Russ AP, Wattler S, Colledge WH, Aparicio SA, Carlton MB, Pearce JJ et al (2000) Eomesodermin is required for mouse trophoblast development and mesoderm formation. Nature 404(6773):95-99

195. Bruce AE, Howley C, Zhou Y, Vickers SL, Silver LM, King ML et al (2003) The maternally expressed zebrafish T-box gene eomesodermin regulates organizer formation. Development (Cambridge, England) 130(22):5503-5517

196. Bjornson CR, Griffin KJ, Farr GH 3rd, Terashima A, Himeda C, Kikuchi $\mathrm{Y}$ et al (2005) Eomesodermin is a localized maternal determinant required for endoderm induction in zebrafish. Dev Cell 9(4):523-533

197. Cho KW, Blumberg B, Steinbeisser H, De Robertis EM (1991) Molecular nature of Spemann's organizer: the role of the Xenopus homeobox gene goosecoid. Cell 67(6):1111-1120

198. Ruiz i Altaba A, Jessell TM (1992) Pintallavis, a gene expressed in the organizer and midline cells of frog embryos: involvement in the development of the neural axis. Development (Cambridge, England) 116(1):81-93

199. Taira M, Jamrich M, Good PJ, Dawid IB (1992) The LIM domain-containing homeo box gene Xlim-1 is expressed specifically in the organizer region of Xenopus gastrula embryos. Genes Dev 6(3):356-366

200. von Dassow G, Schmidt JE, Kimelman D (1993) Induction of the Xenopus organizer: expression and regulation of Xnot, a novel FGF and activin-regulated homeo box gene. Genes Dev 7(3):355-366

201. Glavic A, Gomez-Skarmeta JL, Mayor R (2001) Xiro-1 controls mesoderm patterning by repressing bmp-4 expression in the Spemann organizer. Dev Dyn 222(3):368-376

202. Carlsson P, Mahlapuu M (2002) Forkhead transcription factors: key players in development and metabolism. Dev Biol 250(1):1-23

203. Suri C, Haremaki T, Weinstein DC (2004) Inhibition of mesodermal fate by Xenopus HNF3beta/FoxA2. Dev Biol 265(1):90-104

204. Frank D, Harland RM (1991) Transient expression of XMyoD in non-somitic mesoderm of Xenopus gastrulae. Development (Cambridge, England) 113(4):1387-1393

205. Gawantka V, Delius H, Hirschfeld K, Blumenstock C, Niehrs C (1995) Antagonizing the Spemann organizer: role of the homeobox gene Xvent-1. EMBO J 14(24):6268-6279

206. Ault KT, Dirksen ML, Jamrich M (1996) A novel homeobox gene PV.1 mediates induction of ventral mesoderm in Xenopus embryos. Proc Natl Acad Sci USA 93(13):6415-6420

207. Onichtchouk D, Gawantka V, Dosch R, Delius H, Hirschfeld K, Blumenstock C et al (1996) The Xvent-2 homeobox gene is part of the BMP-4 signalling pathway controlling [correction of controling] dorsoventral patterning of Xenopus mesoderm. Development (Cambridge, England) 122(10):3045-3053

208. Schmidt JE, von Dassow G, Kimelman D (1996) Regulation of dorsal-ventral patterning: the ventralizing effects of the novel Xenopus homeobox gene Vox. Development (Cambridge, England) 122(6):1711-1721

209. Amaya E, Stein PA, Musci TJ, Kirschner MW (1993) FGF signalling in the early specification of mesoderm in Xenopus. Development (Cambridge, England) 118(2):477-487

210. Hopwood ND, Pluck A, Gurdon JB (1991) Xenopus Myf-5 marks early muscle cells and can activate muscle genes 
ectopically in early embryos. Development (Cambridge, England) 111(2):551-560

211. Watanabe M, Rebbert ML, Andreazzoli M, Takahashi N, Toyama R, Zimmerman S et al (2002) Regulation of the Lim-1 gene is mediated through conserved FAST-1/FoxH1 sites in the first intron. Dev Dyn 225(4):448-456

212. Steinbeisser H, Fainsod A, Niehrs C, Sasai Y, De Robertis EM (1995) The role of gsc and BMP-4 in dorsal-ventral patterning of the marginal zone in Xenopus: a loss-of-function study using antisense RNA. EMBO J 14(21):5230-5243

213. Ferreiro B, Artinger M, Cho K, Niehrs C (1998) Antimorphic goosecoids. Development (Cambridge, England) 125(8):1347-1359

214. Latinkic BV, Smith JC (1999) Goosecoid and mix.1 repress Brachyury expression and are required for head formation in Xenopus. Development (Cambridge, England) 126(8):1769-1779

215. Talbot WS, Trevarrow B, Halpern ME, Melby AE, Farr G, Postlethwait JH et al (1995) A homeobox gene essential for zebrafish notochord development. Nature 378(6553):150-157

216. Sander V, Reversade B, De Robertis EM (2007) The opposing homeobox genes Goosecoid and Vent1/2 self-regulate Xenopus patterning. EMBO J 26(12):2955-2965

217. Shawlot W, Behringer RR (1995) Requirement for Lim1 in head-organizer function. Nature 374(6521):425-430

218. Ang SL, Rossant J (1994) HNF-3 beta is essential for node and notochord formation in mouse development. Cell 78(4):561-574

219. Weinstein DC, Ruiz i Altaba A, Chen WS, Hoodless P, Prezioso VR, Jessell TM et al (1994) The winged-helix transcription factor HNF-3 beta is required for notochord development in the mouse embryo. Cell. 78(4):575-588

220. Rivera-Perez JA, Mallo M, Gendron-Maguire M, Gridley T, Behringer RR (1995) Goosecoid is not an essential component of the mouse gastrula organizer but is required for craniofacial and rib development. Development (Cambridge, England) 121(9):3005-3012

221. Yamada G, Mansouri A, Torres M, Stuart ET, Blum M, Schultz M et al (1995) Targeted mutation of the murine goosecoid gene results in craniofacial defects and neonatal death. Development (Cambridge, England) 121(9):2917-2922

222. Dufort D, Schwartz L, Harpal K, Rossant J (1998) The transcription factor HNF3beta is required in visceral endoderm for normal primitive streak morphogenesis. Development (Cambridge, England) 125(16):3015-3025

223. Perea-Gomez A, Shawlot W, Sasaki H, Behringer RR, Ang S (1999) HNF3beta and Lim1 interact in the visceral endoderm to regulate primitive streak formation and anterior-posterior polarity in the mouse embryo. Development (Cambridge, England) 126(20):4499-4511

224. Sassoon D, Lyons G, Wright WE, Lin V, Lassar A, Weintraub H et al (1989) Expression of two myogenic regulatory factors myogenin and MyoD1 during mouse embryogenesis. Nature 341(6240):303-307

225. Braun T, Bober E, Buschhausen-Denker G, Kohtz S, Grzeschik KH, Arnold HH (1989) Differential expression of myogenic determination genes in muscle cells: possible autoactivation by the Myf gene products. EMBO J 8(12):3617-3625

226. Onichtchouk D, Glinka A, Niehrs C (1998) Requirement for Xvent- 1 and Xvent-2 gene function in dorsoventral patterning of Xenopus mesoderm. Development (Cambridge, England) 125(8):1447-1456

227. Hwang YS, Seo JJ, Cha SW, Lee HS, Lee SY, Roh DH et al (2002) Antimorphic PV.1 causes secondary axis by inducing ectopic organizer. Biochem Biophys Res Commun 292(4):1081-1086
228. Melby AE, Beach C, Mullins M, Kimelman D (2000) Patterning the early zebrafish by the opposing actions of bozozok and vox/ vent. Dev Biol 224(2):275-285

229. Imai Y, Gates MA, Melby AE, Kimelman D, Schier AF, Talbot WS (2001) The homeobox genes vox and vent are redundant repressors of dorsal fates in zebrafish. Development (Cambridge, England) 128(12):2407-2420

230. Shimizu T, Yamanaka Y, Nojima H, Yabe T, Hibi M, Hirano T (2002) A novel repressor-type homeobox gene, ved, is involved in dharma/bozozok-mediated dorsal organizer formation in zebrafish. Mech Dev 118(1-2):125-138

231. Seebald JL, Szeto DP (2011) Zebrafish eve1 regulates the lateral and ventral fates of mesodermal progenitor cells at the onset of gastrulation. Dev Biol 349(1):78-89

232. Reim G, Brand M (2006) Maternal control of vertebrate dorsoventral axis formation and epiboly by the POU domain protein Spg/Pou2/Oct4. Development (Cambridge, England) 133(14):2757-2770

233. Belting HG, Wendik B, Lunde K, Leichsenring M, Mossner R, Driever W et al (2011) Pou5f1 contributes to dorsoventral patterning by positive regulation of vox and modulation of fgf8a expression. Dev Biol 356(2):323-336

234. Rosa FM (1989) Mix. 1, a homeobox mRNA inducible by mesoderm inducers, is expressed mostly in the presumptive endodermal cells of Xenopus embryos. Cell 57(6):965-974

235. Mead PE, Brivanlou IH, Kelley CM, Zon LI (1996) BMP-4responsive regulation of dorsal-ventral patterning by the homeobox protein Mix. 1. Nature 382(6589):357-360

236. Wright CV, Schnegelsberg P, De Robertis EM (1989) XIHbox 8: a novel Xenopus homeo protein restricted to a narrow band of endoderm. Development (Cambridge, England) 105(4):787-794

237. Sasai Y, Lu B, Piccolo S, De Robertis EM (1996) Endoderm induction by the organizer-secreted factors chordin and noggin in Xenopus animal caps. EMBO J 15(17):4547-4555

238. Lemaire P, Darras S, Caillol D, Kodjabachian L (1998) A role for the vegetally expressed Xenopus gene Mix.1 in endoderm formation and in the restriction of mesoderm to the marginal zone. Development (Cambridge, England) 125(13):2371-2380

239. Yamamoto S, Hikasa H, Ono H, Taira M (2003) Molecular link in the sequential induction of the Spemann organizer: direct activation of the cerberus gene by Xlim-1, Xotx2, Mix. 1, and Siamois, immediately downstream from Nodal and Wnt signaling. Dev Biol 257(1):190-204

240. de Souza FS, Gawantka V, Gomez AP, Delius H, Ang SL, Niehrs C (1999) The zinc finger gene Xblimp1 controls anterior endomesodermal cell fate in Spemann's organizer. EMBO J 18(21):6062-6072

241. Vize PD (1996) DNA sequences mediating the transcriptional response of the Mix.2 homeobox gene to mesoderm induction. Dev Biol 177(1):226-231

242. Henry GL, Melton DA (1998) Mixer, a homeobox gene required for endoderm development. Science (New York, NY) 281(5373):91-96

243. Casey ES, Tada M, Fairclough L, Wylie CC, Heasman J, Smith JC (1999) Bix4 is activated directly by VegT and mediates endoderm formation in Xenopus development. Development (Cambridge, England) 126(19):4193-4200

244. Kikuchi Y, Trinh LA, Reiter JF, Alexander J, Yelon D, Stainier DY (2000) The zebrafish bonnie and clyde gene encodes a Mix family homeodomain protein that regulates the generation of endodermal precursors. Genes Dev 14(10):1279-1289

245. Poulain M, Lepage T (2002) Mezzo, a paired-like homeobox protein is an immediate target of Nodal signalling and regulates endoderm specification in zebrafish. Development (Cambridge, England) 129(21):4901-4914 
246. Chen X, Weisberg E, Fridmacher V, Watanabe M, Naco G, Whitman M (1997) Smad4 and FAST-1 in the assembly of activin-responsive factor. Nature 389(6646):85-89

247. Engleka MJ, Craig EJ, Kessler DS (2001) VegT activation of Sox17 at the midblastula transition alters the response to nodal signals in the vegetal endoderm domain. Dev Biol 237(1):159-172

248. Zorn AM, Barish GD, Williams BO, Lavender P, Klymkowsky MW, Varmus HE (1999) Regulation of Wnt signaling by Sox proteins: XSox17 alpha/beta and XSox3 physically interact with beta-catenin. Mol Cell 4(4):487-498

249. Sinner D, Rankin S, Lee M, Zorn AM (2004) Sox 17 and betacatenin cooperate to regulate the transcription of endodermal genes. Development (Cambridge, England) 131(13):3069-3080

250. Zhang C, Basta T, Fawcett SR, Klymkowsky MW (2005) SOX7 is an immediate-early target of VegT and regulates Nodal-related gene expression in Xenopus. Dev Biol 278(2):526-541

251. Zhang C, Basta T, Jensen ED, Klymkowsky MW (2003) The beta-catenin/VegT-regulated early zygotic gene Xnr5 is a direct target of SOX3 regulation. Development (Cambridge, England) 130(23):5609-5624

252. Zhang C, Klymkowsky MW (2007) The Sox axis, Nodal signaling, and germ layer specification. Differentiation 75(6):536-545

253. Afouda BA, Ciau-Uitz A, Patient R (2005) GATA4, 5 and 6 mediate TGFbeta maintenance of endodermal gene expression in Xenopus embryos. Development (Cambridge, England) 132(4):763-774

254. Reiter JF, Alexander J, Rodaway A, Yelon D, Patient R, Holder $\mathrm{N}$ et al (1999) Gata5 is required for the development of the heart and endoderm in zebrafish. Genes Dev 13(22):2983-2995

255. Jones CM, Broadbent J, Thomas PQ, Smith JC, Beddington RS (1999) An anterior signalling centre in Xenopus revealed by the homeobox gene XHex. Curr Biol 9(17):946-954

256. Brickman JM, Jones CM, Clements M, Smith JC, Beddington RS (2000) Hex is a transcriptional repressor that contributes to anterior identity and suppresses Spemann organiser function. Development (Cambridge, England) 127(11):2303-2315

257. Zamparini AL, Watts T, Gardner CE, Tomlinson SR, Johnston GI, Brickman JM (2006) Hex acts with beta-catenin to regulate anteroposterior patterning via a Groucho-related co-repressor and Nodal. Development (Cambridge, England) 133(18):3709-3722

258. Viotti M, Nowotschin S, Hadjantonakis AK (2014) SOX17 links gut endoderm morphogenesis and germ layer segregation. Nat Cell Biol 16(12):1146-1156

259. Pohl BS, Rossner A, Knochel W (2005) The Fox gene family in Xenopus laevis:FoxI2, FoxM1 and FoxP1 in early development. Int J Dev Biol 49(1):53-58

260. Suri C, Haremaki T, Weinstein DC (2005) Xema, a foxi-class gene expressed in the gastrula stage Xenopus ectoderm, is required for the suppression of mesendoderm. Development (Cambridge, England) 132(12):2733-2742

261. Cha SW, McAdams M, Kormish J, Wylie C, Kofron M (2012) Foxi2 is an animally localized maternal mRNA in Xenopus, and an activator of the zygotic ectoderm activator Foxile. PLoS One 7(7):e41782

262. Mir A, Kofron M, Zorn AM, Bajzer M, Haque M, Heasman J et al (2007) FoxIle activates ectoderm formation and controls cell position in the Xenopus blastula. Development (Cambridge, England) 134(4):779-788

263. Shih YH, Kuo CL, Hirst CS, Dee CT, Liu YR, Laghari ZA et al (2010) SoxB1 transcription factors restrict organizer gene expression by repressing multiple events downstream of Wnt signalling. Development (Cambridge, England) 137(16):2671-2681
264. Kuo CL, Lam CM, Hewitt JE, Scotting PJ (2013) Formation of the embryonic organizer is restricted by the competitive influences of Fgf signaling and the SoxB1 transcription factors. PLoS One 8(2):e57698

265. Spemann (1901) Über Correlationen in der Entwicklung des Auges. Verh Anat Ges 15:61-79

266. Dale L, Smith JC, Slack JM (1985) Mesoderm induction in Xenopus laevis: a quantitative study using a cell lineage label and tissue-specific antibodies. $\mathrm{J}$ Embryol Exp Morphol 89:289-312

267. Grainger RM, Gurdon JB (1989) Loss of competence in amphibian induction can take place in single nondividing cells. Proc Natl Acad Sci USA 86(6):1900-1904

268. Lettice LA, Slack JM (1993) Properties of the dorsalizing signal in gastrulae of Xenopus laevis. Development (Cambridge, England) 117(1):263-271

269. Grimm OH, Gurdon JB (2002) Nuclear exclusion of Smad2 is a mechanism leading to loss of competence. Nat Cell Biol 4(7):519-522

270. Steinbach OC, Wolffe AP, Rupp RA (1997) Somatic linker histones cause loss of mesodermal competence in Xenopus. Nature 389(6649):395-399

271. Lim CY, Reversade B, Knowles BB, Solter D (2013) Optimal histone $\mathrm{H} 3$ to linker histone $\mathrm{H} 1$ chromatin ratio is vital for mesodermal competence in Xenopus. Development (Cambridge, England) 140(4):853-860

272. Szenker E, Lacoste N, Almouzni G (2012) A developmental requirement for HIRA-dependent H3.3 deposition revealed at gastrulation in Xenopus. Cell Rep 1(6):730-740

273. Tada M, O'Reilly MA, Smith JC (1997) Analysis of competence and of Brachyury autoinduction by use of hormone-inducible Xbra. Development (Cambridge, England) 124(11):2225-2234

274. Domingo C, Keller R (2000) Cells remain competent to respond to mesoderm-inducing signals present during gastrulation in Xenopus laevis. Dev Biol 225(1):226-240

275. Chang C, Harland RM (2007) Neural induction requires continued suppression of both Smad1 and Smad2 signals during gastrulation. Development (Cambridge, England) 134(21):3861-3872

276. Buitrago-Delgado E, Nordin K, Rao A, Geary L, LaBonne C (2015) Neurodevelopment. Shared regulatory programs suggest retention of blastula-stage potential in neural crest cells. Science (New York, NY) 348(6241):1332-1335

277. Sokol S, Melton DA (1991) Pre-existent pattern in Xenopus animal pole cells revealed by induction with activin. Nature 351(6325):409-411

278. Kinoshita K, Asashima M (1995) Effect of activin and lithium on isolated Xenopus animal blastomeres and response alteration at the midblastula transition. Development (Cambridge, England) 121(6): 1581-1589

279. Cui Y, Tian Q, Christian JL (1996) Synergistic effects of Vg1 and Wnt signals in the specification of dorsal mesoderm and endoderm. Dev Biol 180(1):22-34

280. Cornell RA, Musci TJ, Kimelman D (1995) FGF is a prospective competence factor for early activin-type signals in Xenopus mesoderm induction. Development (Cambridge, England) 121(8):2429-2437

281. Arendt D, Nubler-Jung K (1999) Rearranging gastrulation in the name of yolk: evolution of gastrulation in yolk-rich amniote eggs. Mech Dev 81(1-2):3-22

282. Selleck MA, Stern CD (1991) Fate mapping and cell lineage analysis of Hensen's node in the chick embryo. Development (Cambridge, England) 112(2):615-626

283. Psychoyos D, Stern CD (1996) Fates and migratory routes of primitive streak cells in the chick embryo. Development (Cambridge, England) 122(5):1523-1534 
284. Cooke J, Takada S, McMahon A (1994) Experimental control of axial pattern in the chick blastoderm by local expression of Wnt and activin: the role of HNK-1 positive cells. Dev Biol 164(2):513-527

285. Stern CD, Yu RT, Kakizuka A, Kintner CR, Mathews LS, Vale WW et al (1995) Activin and its receptors during gastrulation and the later phases of mesoderm development in the chick embryo. Dev Biol 172(1):192-205

286. Knezevic V, Ranson M, Mackem S (1995) The organizer-associated chick homeobox gene, Gnot1, is expressed before gastrulation and regulated synergistically by activin and retinoic acid. Dev Biol 171(2):458-470

287. Levin M, Johnson RL, Stern CD, Kuehn M, Tabin C (1995) A molecular pathway determining left-right asymmetry in chick embryogenesis. Cell 82(5):803-814

288. Lawson A, Colas JF, Schoenwolf GC (2001) Classification scheme for genes expressed during formation and progression of the avian primitive streak. Anat Rec 262(2):221-226

289. Chapman SC, Schubert FR, Schoenwolf GC, Lumsden A (2002) Analysis of spatial and temporal gene expression patterns in blastula and gastrula stage chick embryos. Dev Biol 245(1):187-199

290. Skromne I, Stern CD (2002) A hierarchy of gene expression accompanying induction of the primitive streak by $\mathrm{Vg} 1$ in the chick embryo. Mech Dev 114(1-2):115-118

291. Bertocchini F, Stern CD (2002) The hypoblast of the chick embryo positions the primitive streak by antagonizing nodal signaling. Dev Cell 3(5):735-744

292. Alvarez IS, Araujo M, Nieto MA (1998) Neural induction in whole chick embryo cultures by FGF. Dev Biol 199(1):42-54

293. Streit A, Berliner AJ, Papanayotou C, Sirulnik A, Stern CD (2000) Initiation of neural induction by FGF signalling before gastrulation. Nature 406(6791):74-78

294. Sheng G, dos Reis M, Stern CD (2003) Churchill, a zinc finger transcriptional activator, regulates the transition between gastrulation and neurulation. Cell 115(5):603-613

295. Roeser T, Stein S, Kessel M (1999) Nuclear beta-catenin and the development of bilateral symmetry in normal and LiCl-exposed chick embryos. Development (Cambridge, England) 126(13):2955-2965

296. Beddington RS, Robertson EJ (1999) Axis development and early asymmetry in mammals. Cell 96(2):195-209

297. Perea-Gomez A, Vella FD, Shawlot W, Oulad-Abdelghani M, Chazaud C, Meno C et al (2002) Nodal antagonists in the anterior visceral endoderm prevent the formation of multiple primitive streaks. Dev Cell 3(5):745-756
298. Kimura-Yoshida C, Nakano H, Okamura D, Nakao K, Yonemura S, Belo JA et al (2005) Canonical Wnt signaling and its antagonist regulate anterior-posterior axis polarization by guiding cell migration in mouse visceral endoderm. Dev Cell 9(5):639-650

299. Brennan J, Lu CC, Norris DP, Rodriguez TA, Beddington RS, Robertson EJ (2001) Nodal signalling in the epiblast patterns the early mouse embryo. Nature 411(6840):965-969

300. Winnier G, Blessing M, Labosky PA, Hogan BL (1995) Bone morphogenetic protein- 4 is required for mesoderm formation and patterning in the mouse. Genes Dev 9(17):2105-2116

301. Popperl H, Schmidt C, Wilson V, Hume CR, Dodd J, Krumlauf $\mathrm{R}$ et al (1997) Misexpression of Cwnt8C in the mouse induces an ectopic embryonic axis and causes a truncation of the anterior neuroectoderm. Development (Cambridge, England) 124(15):2997-3005

302. Liu P, Wakamiya M, Shea MJ, Albrecht U, Behringer RR, Bradley A (1999) Requirement for Wnt3 in vertebrate axis formation. Nat Genet 22(4):361-365

303. Ueno S, Weidinger G, Osugi T, Kohn AD, Golob JL, Pabon L et al (2007) Biphasic role for Wnt/beta-catenin signaling in cardiac specification in zebrafish and embryonic stem cells. Proc Natl Acad Sci USA 104(23):9685-9690

304. Nostro MC, Cheng X, Keller GM, Gadue P (2008) Wnt, activin, and BMP signaling regulate distinct stages in the developmental pathway from embryonic stem cells to blood. Cell Stem Cell 2(1):60-71

305. Park JR, Jung JW, Lee YS, Kang KS (2008) The roles of Wnt antagonists Dkk1 and sFRP4 during adipogenesis of human adipose tissue-derived mesenchymal stem cells. Cell Prolif 41(6):859-874

306. Kubo A, Shinozaki K, Shannon JM, Kouskoff V, Kennedy M, Woo $S$ et al (2004) Development of definitive endoderm from embryonic stem cells in culture. Development (Cambridge, England) 131(7):1651-1662

307. Lindsley RC, Gill JG, Kyba M, Murphy TL, Murphy KM (2006) Canonical Wnt signaling is required for development of embryonic stem cell-derived mesoderm. Development (Cambridge, England) 133(19):3787-3796

308. Murry CE, Keller G (2008) Differentiation of embryonic stem cells to clinically relevant populations: lessons from embryonic development. Cell 132(4):661-680

309. Warmflash A, Sorre B, Etoc F, Siggia ED, Brivanlou AH (2014) A method to recapitulate early embryonic spatial patterning in human embryonic stem cells. Nat Methods 11(8):847-854 